\title{
Noradrenaline Acting on Alpha1 Adrenoceptor as well as by Chelating Iron Reduces Oxidative Burden on the Brain: Implications With Rapid Eye Movement Sleep
}

\author{
Abhishek Singh ${ }^{\dagger}$, Gitanjali Das ${ }^{\dagger \neq}$, Manjeet Kaur and Birendra N. Mallick* \\ School of Life Sciences, Jawaharlal Nehru University, New Delhi, India
}

The noradrenaline (NA) level in the brain is reduced during rapid eye movement sleep

OPEN ACCESS

Edited by:

Teresa Duda,

Salus University, United States

Reviewed by:

Elisabetta Coppi,

Università degli Studi di Firenze, Italy

Niamh M. C. Connolly,

Royal College of Surgeons in Ireland,

Ireland

*Correspondence:

Birendra N. Mallick

remsbnm@yahoo.com

${ }^{\dagger}$ These authors have contributed equally to this work

¥Present address:

Gitanjali Das,

Department of Pathology and Cell Biology, Columbia University Medical Centre, New York, NY, United States

Received: 05 October 2018 Accepted: 10 January 2019 Published: 19 February 2019

Citation:

Singh A, Das G, Kaur M and Mallick BN (2019) Noradrenaline Acting on Alpha1 Adrenoceptor as well as by Chelating Iron Reduces

Oxidative Burden on the Brain: Implications With Rapid Eye Movement Sleep.

Front. Mol. Neurosci. 12:7. doi: 10.3389/fnmol.2019.00007
(REMS). However, upon REMS deprivation (REMSD) its level is elevated, which induces apoptosis and the degeneration of neurons in the brain. In contrast, isolated studies have reported that NA possesses an anti-oxidant property, while REMSD reduces lipid peroxidation (LP) and reactive oxygen species (ROS). We argued that an optimum level of NA is likely to play a physiologically beneficial role. To resolve the contradiction and for a better understanding of the role of NA in the brain, we estimated LP and ROS levels in synaptosomes prepared from the brains of control and REMS deprived rats with or without in vivo treatment with either $\alpha 1$-adrenoceptor (AR) antagonist, prazosin (PRZ) or a2-AR agonist, clonidine (CLN). REMSD significantly reduced LP and ROS in synaptosomes; while the effect on LP was ameliorated by both PRZ and CLN; ROS was prevented by CLN only. Thereafter, we evaluated in vitro the effects of NA, vitamin $E$ (Vit E), vitamin C (Vit C), and desferrioxamine (DFX, iron chelator) in modulating hydrogen peroxide $\left(\mathrm{H}_{2} \mathrm{O}_{2}\right)$-induced LP and ROS in rat brain synaptosomes, Neuro2a, and C6 cells. We observed that NA prevented ROS generation by chelating iron (inhibiting a Fenton reaction). Also, interestingly, a lower dose of NA protected the neurons and glia, while a higher dose damaged the neurons and glia. These in vitro and in vivo results are complementary and support our contention. Based on the findings, we propose that REMS maintains an optimum level of NA in the brain (an antioxidant compromised organ) to protect the latter from continuous oxidative onslaught.

Keywords: catecholamine, C6, cell death, lipid peroxidation, oxidative stress, synaptosome, vitamins C and E, Neuro2a

Abbreviations: AR, adrenoceptor; BHT, butylated hydroxyl-toluene; CLN, clonidine; DAPI, 6-diamidino-2-phenylindole dihydrochloride; DCF, dichlorofluorescein; DCF-DA, $2^{\prime}, 7^{\prime}$-dichlorofluorescein diacetate; DCFH, reduced dichlorofluorescein; DFX, desferrioxamine; DMEM, Dulbecco modified Eagle's medium; DMSO, Dimethyl sulfoxide; FBS, fetal bovine serum; $\mathrm{FeCl}_{3}$, ferric chloride; $\mathrm{FeSO}_{4}$, ferrous sulfate; $\mathrm{FMC}$, free moving control; $\mathrm{FZ}$, ferrozine; $\mathrm{H}_{2} \mathrm{O}_{2}$, hydrogen peroxide; $\mathrm{LP}$, lipid peroxidation; LPC, large platform control; MDA, malonyldehyde; MTT, 3-(4,5-dimethylthiazol-2-yl)-2,5-diphenyltetrazolium bromide; NA, noradrenaline; PBS, phosphate buffer saline; PI, propidium iodide; PRP, propranolol; PRZ, prazosin; REC, recovery control; REMS, rapid eye movement sleep; REMSD, REMS deprivation; ROS, reactive oxygen species; TBA, thiobarbituric acid; TCA, trichloracetic acid; Vit C, vitamin C; Vit E, vitamin E. 


\section{INTRODUCTION}

The brain is metabolically highly active, resulting in the continuous production of a high amount of reactive oxygen species (ROS; Vallyathan and Shi, 1997; Seaver and Imlay, 2004), whose level is proportional to the neuronal activities (Dugan et al., 1995; Demaurex and Scorrano, 2009). On the other hand, as compared to other organs of the body, the brain possesses the least antioxidants (Friedman, 2011; Lalkovicova and Danielisova, 2016) while it is rich in iron (Keen et al., 1985; Wang et al., 2016b). These factors render the brain extremely vulnerable to oxidative insults (Friedman, 2011). The ROS induces membranelipid peroxidation (LP) and -rigidity, causing damage to DNA as well as proteins leading to neurodegeneration (Dröge and Schipper, 2007), acute, and chronic disorders (Valko et al., 2004; Galli et al., 2005). Therefore, we argued that the brain possibly possesses a unique mechanism associated with a unique instinct behavior that it controls to address and protect itself from oxidative onslaught.

The brain is rich in monoaminergic neurotransmitters including noradrenaline (NA), dopamine, serotonin and melatonin, which possess antioxidant property and may offer protection to the brain (Yen and Hsieh, 1997; Gulçin, 2008). Indeed, independent studies have shown that NA, by reducing LP and ROS generation, may protect the neurons (Troadec et al., 2001; Traver et al., 2005; Das et al., 2008). Rapid eye movement sleep (REMS), a unique behavior, normally maintains brain NA level (Mallick and Singh, 2011; Mallick et al., 2012). However, upon REMS deprivation (REMSD), the NA level is elevated in the brain (Porkka-Heiskanen et al., 1995; Mehta et al., 2017) and that by acting on adrenoceptor (AR) induces REMSDassociated neuronal damage (Majumdar and Mallick, 2005; Biswas et al., 2006; Jaiswal and Mallick, 2009; Ranjan et al., 2010; Somarajan et al., 2016). These isolated, independent, apparently contradictory findings raise an intriguing but fundamental question: what basic purpose does NA serve in the brain so that its level changes through sleep-waking-REMS states? Additional evidence was needed to reconcile why although NA exerts neuro-protection (Troadec et al., 2001; Traver et al., 2005; Patri et al., 2013), upon REMSD-elevated NA induces apoptosis and neurodegeneration (Biswas et al., 2006; Somarajan et al., 2016). To address these issues, we conducted in vivo and in vitro studies to understand the possible beneficial effect of NA and its possible mechanism of action.

Independent studies have shown that iron $\left(\mathrm{Fe}^{2+}\right)$ induces ROS (Chung et al., 2005; Wang et al., 2016a) and its (iron) deficiency aggravates restless leg syndrome, which is associated with REMS-loss when the NA level rises (Porkka-Heiskanen et al., 1995; Lee et al., 2001; Allen and Earley, 2007; Patrick, 2007; Auerbach, 2014; Connor et al., 2017; Mehta et al., 2017). Therefore, we proposed that at the molecular level NA might modulate $\mathrm{Fe}^{2+}$, ROS, and membrane LP to alter their equilibrium (relative levels) and depending on the shift in equilibrium, it would provide either neuronal protection or damage. In this study, using in vivo (rat) and in vitro (synaptosomes and cell-lines) complementary models, we explored if the REMSDassociated elevated NA-induced neuronal damage was mediated by modulating $\mathrm{Fe}^{2+}$ and ROS levels. First, we evaluated the effects of REMSD and NA on ROS and LP levels in rat brain synaptosomes with particular reference to AR-subtype involved in the process. To explore the effectiveness of the anti-oxidative property of NA, we compared the effects of NA, vitamin (Vit) $\mathrm{E}$, and Vit $\mathrm{C}$ alone, as well as upon hydrogen peroxide $\left(\mathrm{H}_{2} \mathrm{O}_{2}\right)$ induced ROS generation in synaptosomes prepared from rat brain. As a mechanism of action, we also observed that NA chelated $\mathrm{Fe}^{2+}$ and prevented ROS generation by inhibiting the Fenton reaction. Thereafter, in Neuro2a and C6 cells we confirmed that NA indeed reduced ROS generation in normal as well as in $\mathrm{H}_{2} \mathrm{O}_{2}$-treated cells and protected them from death. Our findings offer a long overdue molecular mechanism of NA-induced protection of the brain (neurons and glia) as well as the role of REMS in maintaining brain NA level in health and diseases.

\section{MATERIALS AND METHODS}

\section{Materials}

Clonidine (CLN), 6-diamidino-2-phenylindole dihydrochloride (DAPI), 2', $7^{\prime}$-dichlorofluorescin diacetate (DCF-DA), desferrioxamine (DFX), Dulbecco modified Eagle's medium (DMEM), ferrozine (FZ), $\mathrm{H}_{2} \mathrm{O}_{2}, 3$-(4,5-dimethylthiazol-2yl)-2,5-diphenyltetrazolium bromide (MTT), NA, propidium iodide (PI), propranolol (PRP), prazosin (PRZ), thiobarbituric acid (TBA), Vit C, Vit E were procured from Sigma-Aldrich, St. Louis, MO, USA. Butylated hydroxyl-toluene (BHT), ferrous sulfate $\left(\mathrm{FeSO}_{4}\right)$, ferric chloride $\left(\mathrm{FeCl}_{3}\right)$ and iron/ferrous $\left(\mathrm{Fe}^{2+}\right)$ chelator FZ, trichloracetic acid (TCA) were procured from Sisco Research Laboratories (SRL) India. All other chemicals were of analytical grade and were locally purchased.

\section{Animals}

Fifty-five male inbred wistar rats (Rattus norvegicus; 250-280 g, which corresponds to approx. 6-month-old rats) obtained from the animal house facility of the Jawaharlal Nehru University were used in the study. The rats were randomly distributed into eight groups of five animals each for in vivo studies, while the rest were used to prepare synaptosomes for in vitro studies. They were maintained at a 12/12 h light/dark cycle and supplied with food and water ad libitum. The NIH guidelines National Research Council Guidelines (2011; Guide for the Care and Use of Laboratory Animals ${ }^{1}$ ) for the humane carrying out of research on animals have been followed and all the experimental protocols were approved by the Institutional Animal Ethics Committee of the Jawaharlal Nehru University. Every effort was made to use a minimum number of rats and to minimize pain and discomfort to the experimental rats while acquiring statistically acceptable data.

The standard flower-pot method was used for 4-days REMSD as reported earlier (Gulyani and Mallick, 1993; Das and Mallick, 2008; Somarajan et al., 2016). In brief, for REMSD the rats were maintained on a small $(6.5 \mathrm{~cm}$ diameter $)$ platform raised over surrounding water. To rule out non-specific effects, a

\footnotetext{
${ }^{1}$ http://www.ncbi.nlm.nih.gov/books/NBK54050/ doi: 10.17226/12910
} 
group of rats were maintained in the same room on a larger (13 cm diameter) platform (LPC) raised over water under identical environmental conditions. Freely moving normal home cage grown rats (FMC) were used for collecting baseline data. Another control set, the recovery group (REC) included rats deprived of REMS for 4 days and then allowed 3 days in their normal home cages to recover from lost REMS. Thus, every set of experiment included one rat each of FMC, LPC, REMSD, and REC groups and five such sets were carried out. Additionally, to study the AR subtype involved for the action of NA, in another five sets of two rats each, one FMC and other REMSD rats were intraperitoneally injected with either PRZ ( $4 \mathrm{mg} / \mathrm{kg})$ or CLN $(0.1 \mathrm{mg} / \mathrm{kg}) 8 \mathrm{~h}$ before sacrifice to prevent the action or release of NA, respectively. The dosage and time of PRZ and CLN injections were based on our earlier report (Gulyani and Mallick, 1995).

\section{Synaptosome Preparation}

At the end of the experiments, all the rats were decapitated after cervical dislocation (Mallick and Adya, 1999; Das et al., 2008; Baskey et al., 2009). The brains were quickly removed and homogenized in 10 volumes of ice-cold buffer containing $0.32 \mathrm{M}$ sucrose and $12 \mathrm{mM}$ Tris at $\mathrm{pH} 7.4$ and synaptosomes prepared as described earlier. In brief, the brain homogenate was centrifuged for $5 \mathrm{~min}$ at $6,000 \mathrm{rpm}(3,000 \mathrm{~g})$ and the supernatant was further centrifuged at $12,000 \mathrm{rpm}(11,000 \mathrm{~g})$ for $20 \mathrm{~min}$. The pellet was suspended in $1 \mathrm{ml}$ of the homogenizing buffer, loaded onto $1.2 \mathrm{M}$ and $0.8 \mathrm{M}$ preformed sucrose density gradient and ultra-centrifuged in a swing-out rotor at 25,000 rpm $(100,000 \mathrm{~g})$ for $2 \mathrm{~h}$. The synaptosomal fraction at the interface of $1.2 \mathrm{M}$ and $0.8 \mathrm{M}$ sucrose was re-suspended in the homogenizing buffer and processed for ROS and LP estimations. The synaptosomes were prepared within $2-3 \mathrm{~h}$ of brain extraction and under $4^{\circ} \mathrm{C}$ to minimize the loss of enzyme activities. The protein concentration in the synaptosomes was estimated by the Lowry method (Lowry et al., 1951).

Synaptosomes prepared from FMC rat brains were treated with $\mathrm{H}_{2} \mathrm{O}_{2}$ to induce ROS generation. To study the modulatory effect of NA, Vit E, and Vit C, the synaptosomes from FMC rat brains were first treated with one of these modulators alone or in combination before treating them with $\mathrm{H}_{2} \mathrm{O}_{2}$ and their respective effects on ROS levels estimated; five such sets were conducted. Further, to evaluate the role of iron in modulating the NA-, Vit E-, and Vit C-induced ROS levels, which in turn might influence LP, we estimated ROS levels after treatment with iron chelator, DFX. To minimize the photo-oxidation of NA, we always prepared a fresh NA solution for each experiment and protected it from light exposure until treatment as well as throughout the duration of the treatment.

\section{Estimation of Synaptosomal LP}

Synaptosomal LP was estimated essentially following a (minor modification) previous report (Rehncrona et al., 1980). The synaptosomal sample $(0.4 \mathrm{mg}$ protein) mixed with $0.5 \mathrm{ml}$ of $30 \%$ TCA and $0.5 \mathrm{ml}$ of $52 \mathrm{mM}$ TBA was incubated in a water bath shaker for $45 \mathrm{~min}$ at $80^{\circ} \mathrm{C}$. The tubes were then ice-cooled and centrifuged $(4,000 \mathrm{~g})$ in a refrigerated centrifuge. The absorbance of the supernatant was read using a UV160 spectrophotometer (Shimadzu, Japan) against a blank at $532 \mathrm{~nm}$ and expressed as nmoles malonyldehyde (MDA) $\mathrm{mg}^{-1}$ protein.

\section{Estimation of Synaptosomal ROS}

ROS was estimated (Lebel and Bondy, 1990) using a ROS-sensitive fluorescent probe DCF-DA that diffuses through the membrane. The DCF-DA gets into the synaptosomes and converted into non-fluorescent reduced form of DCF. The latter, in the presence of ROS, gets oxidized into a highly fluorescent form of DCF, which was estimated. First, the synaptosomes (0.05 mg protein) were incubated with DCF-DA at $37^{\circ} \mathrm{C}$ for $15 \mathrm{~min}$ in a water bath. At the end of the treatment, the reaction was terminated by adding $2 \mathrm{ml}$ of ice-cold phosphate buffer $(\mathrm{PB})$ at $\mathrm{pH}$ 7.4. Thereafter, the sample mixture was centrifuged at $12,500 \mathrm{~g}$ for $8 \mathrm{~min}$ and the pellet was resuspended in $2 \mathrm{ml}$ of PB. The DCF fluorescence was estimated as a reflection of ROS generated using a microplate reader (Thermo Scientific Varioskan Flash, Finland) at $488 \mathrm{~nm}$ and $525 \mathrm{~nm}$ for the excitation and emission, respectively.

\section{Cell Culture}

The Neuro2a (RRID:CVCL_0470) and C6 cells (RRID:CVCL_0194) were obtained from the National Centre for Cell Science cell repository (Pune, India). These cells were cultured in DMEM, supplemented with 10\% FBS and $0.1 \%$ penicillin-streptomycin, and incubated in a humidified 95\% air and $5 \% \mathrm{CO}_{2}$ at $37^{\circ} \mathrm{C}$. The cells were sub-cultured once they reached about $80 \%$ confluence.

\section{MTT Cell Viability Assay}

Cell viability was estimated using an MTT assay, which is based on the ability of the viable cells to metabolize MTT into formazan (Mosmann, 1983). Neuro2a and C6 cells $\left(2 \times 10^{4}\right.$ per well) were seeded in a 96 well plate. The effects of $\mathrm{NA}, \mathrm{H}_{2} \mathrm{O}_{2}$, $\mathrm{DFX}, \mathrm{FeSO}_{4}$, and Vit E, as compared to untreated controls, were evaluated for cell viability. After incubation for $24 \mathrm{~h}$ with the test substance, the medium from each well was aspirated. Subsequently, controls as well as treated cells were incubated with the medium containing $5 \mu \mathrm{g} / \mathrm{ml} \mathrm{MTT}$ at $37^{\circ} \mathrm{C}$ for $3 \mathrm{~h}$. Thereafter, the cells were washed twice with $\mathrm{PB}$ saline (PBS), the cellular formazan crystals were solubilized with DMSO and absorbance recorded in a microplate reader (BioTek, Winooski, VT, USA) at $570 \mathrm{~nm}$ with background subtraction at $630 \mathrm{~nm}$. The cell viability in the experimental set has been expressed as a percentage (mean \pm SEM) change relative to the corresponding untreated control set (taken as 100\%).

\section{Estimation of Intracellular ROS in Neuro2a and $\mathrm{C6}$ Cells}

The Neuro2a and C6 cells were grown in separate petri dishes in $\mathrm{a} \mathrm{CO}_{2}$ incubator in a normal and iron-rich $\left(10 \mu \mathrm{M} \mathrm{FeSO}_{4}\right.$ added $)$ medium and were treated with either or in various combinations of NA, Vit E, $\mathrm{H}_{2} \mathrm{O}_{2}$ and DFX for $2 \mathrm{~h}$. The treated cells were washed and incubated in a medium containing $10 \mu \mathrm{M}$ DCF-DA for $20 \mathrm{~min}$. At the end, the cells were washed with an ice cold 
$\mathrm{PB}$ at $\mathrm{pH}$ 7.4. DCF-DA gets into the cells and is converted into a non-fluorescent form DCFH, which in the presence of ROS gets oxidized into highly fluorescent DCF. The intensities of DCF fluorescence in control and treatment groups were estimated using a spectrofluorometer (Agilent Technologies, Palo Alto, CA, USA) as a reflection of the quantity of ROS generated by the cells.

\section{Estimation of LP in Neuro2a and C6 Cells}

Neuro2a and C6 cells $\left(\sim 2 \times 10^{7}\right.$ cells $)$ were plated in separate $100 \mathrm{~mm}$ dishes. Cells were treated either with NA, Vit E, PRZ, PRP, $\mathrm{H}_{2} \mathrm{O}_{2}$ alone or in various combinations. At the end of $12 \mathrm{~h}$ treatment, the cells were washed and pelleted down and $30 \mu \mathrm{l}$ of the BHT solution was added to it to stop further oxidation. Cell suspension was made in $0.5 \mathrm{ml}$ of $30 \%$ TCA. Thereafter, $0.5 \mathrm{ml}$ of $52 \mathrm{mM}$ TBA was added and the mixture was incubated in a water bath shaker for $45 \mathrm{~min}$ at $80^{\circ} \mathrm{C}$. The mixture was then ice-cooled and centrifuged (at $4,000 \mathrm{~g}$ ) at $4^{\circ} \mathrm{C}$ for $15 \mathrm{~min}$. The absorbance of the supernatant was read against a blank at $532 \mathrm{~nm}$ using a microplate reader (BioTek, Winooski, VT, USA) and expressed as nmoles MDA mg ${ }^{-1}$ protein.

\section{Iron $\left(\mathrm{Fe}^{2+}\right)$ Chelation Assay}

$\mathrm{Fe}^{2+}$ chelation studies were performed using the method reported earlier (Dinis et al., 1994). In a separate experiment, $200 \mu \mathrm{L}$ of $10 \mu \mathrm{M}$ to $1 \mathrm{mM}$ of NA was mixed with $20 \mu \mathrm{l}$ of 5-50 $\mu \mathrm{M}$ of either $\mathrm{FeSO}_{4}$ or $\mathrm{FeCl}_{3}$ and allowed to stand at room temperature for $30 \mathrm{~min}$. At the end, $100 \mu \mathrm{l}$ of $1 \mathrm{mM}$ FZ was added to it, shaken vigorously and left for $10 \mathrm{~min}$. The absorbance of the $\mathrm{Fe}^{2+}-\mathrm{FZ}$ complex in the solution was then estimated in a microplate reader (Biotek, Winooski, VT, USA) at $562 \mathrm{~nm}$. All the tests were run in triplicate and their means taken for analyses.

\section{Fluorescence Microscopy for Intracellular DCF Fluorescence}

Neuro2a and C6 cells $\left(2 \times 10^{5}\right.$ cells $)$ were seeded in separate petri-dishes having coated coverslips. Twelve hours of incubation were allowed for the cells to adhere on the coverslips and they were treated for $2 \mathrm{~h}$ either with NA or $\mathrm{H}_{2} \mathrm{O}_{2}$ alone or in combination. The treated and untreated cells were then incubated with a $10 \mu \mathrm{M}$ DCF-DA loading buffer for $30 \mathrm{~min}$, washed and mounted in Mowiol. The cells were manually outlined and the fluorescence per cell was estimated using a fluorescence microscope (Nikon Eclipse 400). One-hundred to one-hundred and twenty cells from 3-4 fields of view from each coverslip per treatment were estimated in duplicate and five such sets of experiments were carried out. The mean background intensity was subtracted to obtain intracellular fluorescence per cell. Mean fluorescence intensities (a.u.) per cell between different treated groups were statistically compared against that of the untreated group.

\section{Estimation (Qualitative) of Dead/Live Cells by PI Staining}

Neuro2a and C6 $\left(2 \times 10^{5}\right.$ cells $)$ were grown on separate coverslips for $12 \mathrm{~h}$ before treating for $24 \mathrm{~h}$ with either NA or $\mathrm{H}_{2} \mathrm{O}_{2}$ alone or both in combination. The cells were then incubated with $500 \mathrm{nM}$ PI (stains nuclei of dead cells) for $30 \mathrm{~min}$ prior to fixing with $4 \%$ paraformaldehyde followed by staining with 30 nM DAPI. The nuclei were stained with DAPI to rule out non-specific PI staining. The images were captured using the Olympus BX51 microscope equipped with a CS9000 camera (MBF bioscience, Williston, VT, USA). The cells stained with both DAPI (blue) and PI (red) were considered to represent dead cells, which needed quantification. However, the PI staining was done on coverslip grown cells, which are prone to and get detached when dead and hence, counting the remaining cells would compromise accuracy in the result. Therefore, we consciously avoided quantifying the PI stained dead cells and instead performed an additional experiment with trypan-blue staining as described below.

\section{Quantification of Dead Cells by Trypan Blue Assay}

Neuro2a and C6 $\left(2 \times 10^{5}\right.$ cells $)$ were separately seeded in 12 -well culture plates for $12 \mathrm{~h}$ and the cells were treated with either $\mathrm{NA}$ or $\mathrm{H}_{2} \mathrm{O}_{2}$ alone or both together for $24 \mathrm{~h}$. The cells were then dissociated, centrifuged and re-suspended in $1 \mathrm{ml}$ PBS. Ten microliter of such cell suspension was then mixed with an equal volume of $0.4 \%$ trypan-blue stain for 3-4 min; the trypan-blue is taken up by the dead cells. Thereafter, the stained (dead) as well as unstained (live) cells (i.e., total number of cells) were counted using a hemeocytometer. The percentage of stained cells to total cells (stained plus unstained) was used as an estimate of dead cells and compared statistically between the treated and untreated cells.

\section{Statistical Analysis}

The data has been presented as mean \pm SEM. A statistical analysis was carried out using SigmaStat 3.0 (RRID:SCR_010285, Jandel Scientific, San Rafael, CA, USA). To compare data from different groups within an experimental set-up, all pairwise multiple comparison test using one way analysis of variance (ANOVA) was applied; it compared values among groups as well as between control and treatments. A Tukey test was applied for evaluating the significance level; at least $p<0.05$ was considered statistically significant. The results of statistical tests have been presented as $F_{(x, y)}$ followed by $p$-values, where $F$ is the ratio of variance between samples or groups and the variance within samples or groups, while $x$ and $y$ are degrees of freedom between the groups and within the groups, respectively.

\section{RESULTS}

\section{Studies in Rat Brain Synaptosomes With or Without Treatment in vivo}

\section{LP and ROS Were Reduced in Synaptosomes Prepared From REMS-Deprived Rats}

$\mathrm{LP}$ and ROS levels $\mathrm{mg}^{-1}$ protein were measured in synaptosomes separately prepared from FMC, LPC, REMSD, and REC rat brains. The group data were significant for both $\operatorname{LP}\left(F_{(3,19)}=33.4\right.$, $p<0.001)$ and $\operatorname{ROS}\left(F_{(3,19)}=5.5, p<0.01\right)$. REMSD significantly 
A

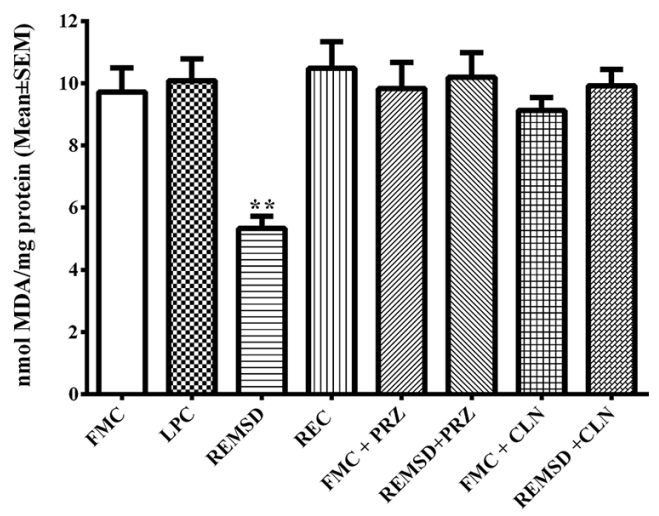

B

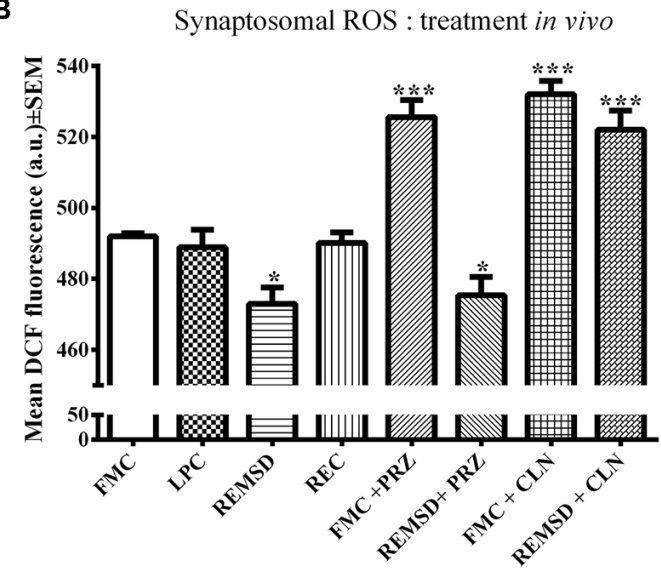

FIGURE 1 | This figure shows relative levels of LP (A) and ROS (B) in the synaptosomes prepared from the brains of controls and REMSD rats which were treated with or without AR alpha2 agonist (CLN) and alpha1antagonist (PRZ). The treatment details have been described in the method (this was done to reconfirm our earlier findings on set conditions Das et al., 2008). Levels of both LP and ROS were significantly reduced after REMSD. While REMSD associated reduction in LP was prevented by both PRZ and CLN (A) reduction in ROS level was prevented by CLN, but not by PRZ. $N=5$ for each set. ${ }^{*} p<0.05,{ }^{* *} p<0.01,{ }^{* * *} p<0.001$ as compared to FMC Abbreviations are as in the text.

decreased the levels of LP $(p<0.001)$ and ROS $(p<0.01)$ in synaptosomes as compared to that of the FMC (Figures 1A,B). Both LP as well as ROS levels in synaptosomes prepared from LPC and REC rat brains were comparable to that of the FMC (Figure 1).

\section{PRZ and CLN Treatments in vivo (i.p.) Prevented REMSD-Induced Reduction in LP and ROS in Rat Brain Synaptosomes}

As an elevated level of NA is a primary and common causative factor for many of the REMSD-induced changes (Mallick and Singh, 2011), we investigated its role as well as involvement of AR-subtype in REMSD-induced changes in LP and ROS levels described above. FMC and REMSD rats were intra-peritoneally (i.p.) treated with PRZ or CLN $8 \mathrm{~h}$ before sacrifice. The LP levels in these treated groups were comparable to that of the FMC, suggesting that both the treatments prevented the REMSD-induced decrease in LP (Figure 1A).

An intraperitoneal injection of either PRZ or CLN into FMC rats significantly $\left(F_{(7,32)}=29.1, p<0.001\right)$ increased ROS levels as compared to untreated FMC rats. The PRZ treatment did not prevent an REMSD-induced reduction in ROS. ROS levels in synaptosomes prepared from CLN-treated REMSD rats were comparable to that of CLN-treated FMC rats (Figure 1B).

\section{Studies Upon Treatment of Synaptosomes in vitro}

\section{NA Reduced LP and ROS in vitro in Synaptosomes Prepared From Normal Rat Brains}

To avoid a non-specific effect of PRZ or PRP in vivo and to understand the specific involvement of AR, the synaptosomes prepared from FMC rat brains were incubated in vitro with either NA, PRZ or PRP and LP as well as ROS levels were compared with untreated synaptosomes taken as controls. As compared to untreated synaptosomes, NA significantly reduced LP $\left(F_{(1,8)}=68.8, p<0.001\right)$. Although PRZ $\left(F_{(1,8)}=6.4\right.$, $p<0.05)$ prevented the NA-induced decrease in LP, PRP was ineffective (Figure 2A).

Synaptosomes incubated with NA also showed significantly decreased levels of $\operatorname{ROS}\left(F_{(1,8)}=85.8, p<0.001\right)$. However, the NA-induced decreased ROS levels were not prevented by either PRZ or PRP treatment (Figure 2B).

\section{$\mathrm{NA}$ and Vit $\mathrm{E}$ Reduced ROS in $\mathrm{H}_{2} \mathrm{O}_{2}$-Treated Synaptosomes in vitro}

We observed in this study (above) that the effect of NA on ROS was not modulated by PRZ or PRP; however, independent reports supported the protective role of NA from the oxidative burden. Therefore, we compared the antioxidative property of NA and other known antioxidants (Vit $\mathrm{C}$ and Vit E) on normal as well as on $\mathrm{H}_{2} \mathrm{O}_{2}$-induced LP and ROS in vitro in isolated synaptosomes from normal FMC rat brains. As a group, LP was significantly $\left(F_{(7,32)}=99.0\right.$, $p<0.001)$ affected. Independently, NA $(p<0.05)$ and Vit $\mathrm{E}(p<0.05)$ significantly decreased, while $\mathrm{H}_{2} \mathrm{O}_{2}$ significantly $(p<0.001)$ increased LP in synaptosomes prepared from normal FMC rat brain as compared to the untreated synaptosmes. Further, although NA and Vit E prevented, Vit C significantly $(p<0.001)$ enhanced the effects of $\mathrm{H}_{2} \mathrm{O}_{2}$-induced LP in synaptosomes (Figure 2C).

The ROS levels among control and different treated groups showed significant change $\left(F_{(7,48)}=54.85, p<0.001\right.$; Figure 2D). As compared to the untreated (CTRL) synaptosomes, the ROS level significantly decreased upon treatment with NA $(p<0.001)$, while it significantly increased when treated with $\mathrm{H}_{2} \mathrm{O}_{2}(p<0.001)$ or Vit $\mathrm{C}(p<0.001)$; Vit E was ineffective. The $\mathrm{H}_{2} \mathrm{O}_{2}$-induced increase in ROS level was prevented by pre-treatment of the synaptosomes with either NA or Vit E; while, Vit $\mathrm{C}$ enhanced $(p<0.001)$ the effect of $\mathrm{H}_{2} \mathrm{O}_{2}$ on ROS levels. 
A Synaptosomal LP: treatments in vitro

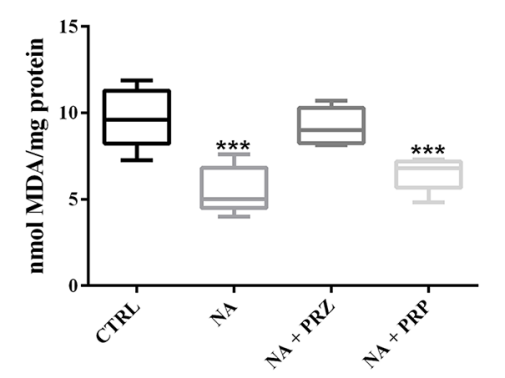

C Synaptosomal LP: treatments in vitro

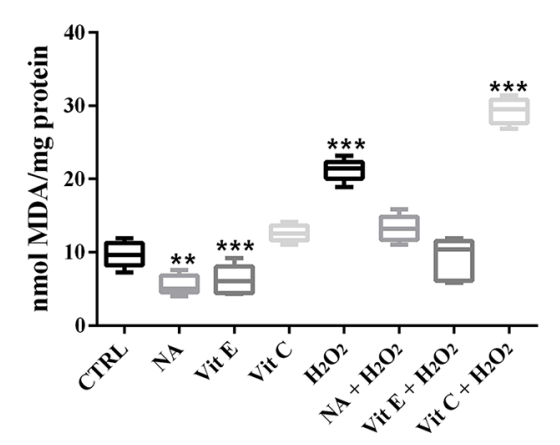

B

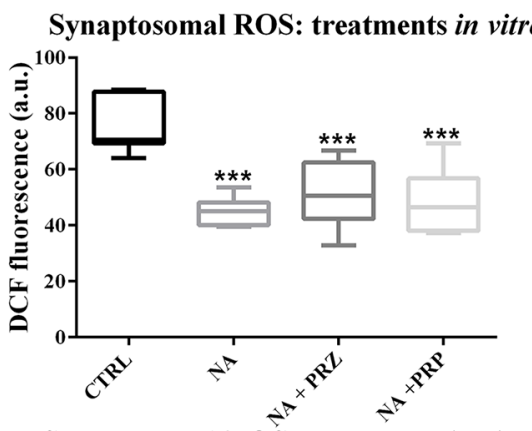

D Synaptosomal ROS: treatments in vitro

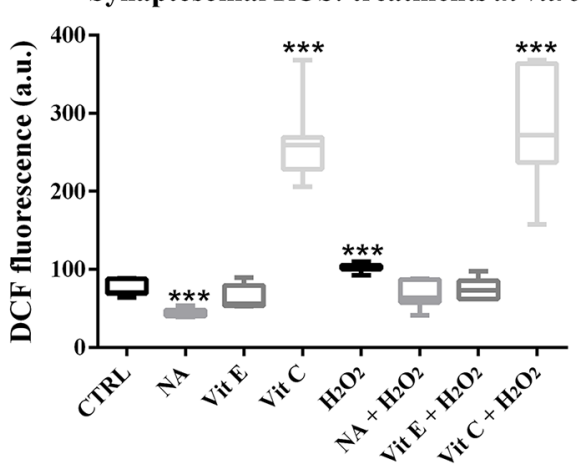

FIGURE 2 | Changes in LP and ROS levels in synaptosomes, which were prepared from FMC rat brains and treated in vitro are shown as box-plots. NA (100 $\mu$ M) significantly decreased both LP and ROS. Although the effect on LP was prevented by PRZ and not by PRP (A), $\alpha 1$ - and B-AR antagonist, respectively, they were ineffective in preventing NA-induce decrease in ROS (B). The effects of NA, Vit E and Vit C on normal and $\mathrm{H}_{2} \mathrm{O}_{2}$-induced changes in synaptosomal LP and ROS have been compared and shown in (C,D) respectively. $\mathrm{H}_{2} \mathrm{O}_{2}$ increased $\mathrm{LP}$ as well as ROS levels, which were although prevented by pre-treating the synaptosomes with Vit $\mathrm{E}$ or $\mathrm{NA}$, the effects were further enhanced if the samples were pre-treated with Vit $\mathrm{C}$. $N=5$ for each set $\mathrm{LP}$, while $N=7$ for ROS. ${ }^{* *} p<0.01$,

${ }^{* * *} p<0.001$ as compared to control. Abbreviations are as in the text.

\section{In vitro Cell Culture Studies}

\section{Neuro2a and C6 Cell Viability Was Dependent on NA Doses}

Dose responses of $\mathrm{H}_{2} \mathrm{O}_{2}$ and NA on Neuro2a and C6 cell viability were tested using an MTT assay. Neuro2a and C6 cells were treated with 0.1-1 $\mathrm{mM} \mathrm{H}_{2} \mathrm{O}_{2}$ or NA (doses are shown in the Figures $3 \mathbf{A}, \mathbf{B})$ for $12 \mathrm{~h}$ and $24 \mathrm{~h}$. The viability of neither Neuro2a (Figure 3A) nor C6 (Figure 3B) cells was affected by low doses (up to $10 \mu \mathrm{M}$ ) of NA; however, it was reduced upon exposure to higher doses $(>10 \mu \mathrm{M})$ of NA and $\mathrm{H}_{2} \mathrm{O}_{2}$ for $24 \mathrm{~h}$. Morphological features of the cultured cells like surface granulation, relative roundedness and their increased non-adherence (detachment) to the plate surface in the presence of $\mathrm{H}_{2} \mathrm{O}_{2}$ suggested cellular stress and damage, which were prevented if the cells were pre-treated with 10 $\mu \mathrm{M}$ NA (Figure 3C). Based on the dose response findings (Figure 3), we used $10 \mu \mathrm{M}$ NA for assessing its protective role on $\mathrm{H}_{2} \mathrm{O}_{2}$-induced oxidative damage in Neuro2a and C6 cells.

\section{NA (Alpha1 AR Mediated) and Vit E Prevented $\mathrm{H}_{2} \mathrm{O}_{2}$-Induced LP in Neuro2a and C6 Cells}

A group comparison showed that LP was significantly modulated when Neuro2a $\left(F_{(9,50)}=5.3, p<0.001\right)$ and C6 $\left(F_{(9,50)}=15.5\right.$, $p<0.001)$ cells were treated with Vit $\mathrm{E}, \mathrm{NA}, \mathrm{PRZ}$, and $\mathrm{H}_{2} \mathrm{O}_{2}$. By and large, $\mathrm{H}_{2} \mathrm{O}_{2}$ significantly $(p<0.001)$ increased, Vit $\mathrm{E}$ significantly $(p<0.001)$ decreased (only in Neuro2a), while NA and PRZ were ineffective in modulating LP as compared to untreated controls. Further, NA significantly $(p<0.001)$ reduced $\mathrm{H}_{2} \mathrm{O}_{2}$-induced LP and such a protective effect of NA was lost when the cell lines were pre-treated with PRZ (Figures 4A,B). As PRP was ineffective on LP in synaptosomes, we did not consider it necessary to study its effects on LP on cell lines. This suggested that, by and large, the NA-induced effect on LP was alpha1 AR mediated. Notwithstanding this, on closer look it may be seen that, as an exception, PRZ exaggerated the action of $\mathrm{H}_{2} \mathrm{O}_{2}$ even in the presence of NA (Figure 4B), which needs further investigation to understand the mechanism of action. Thus, Vit E and NA behaved similarly and acted analogously to antioxidant against $\mathrm{H}_{2} \mathrm{O}_{2}$-induced LP in both cell lines. As Vit $\mathrm{C}$ was not effective, rather it potentiated the $\mathrm{H}_{2} \mathrm{O}_{2}$-induced damaging effect in synaptosomes, we did not test its effect on cell culture studies.

\section{NA (AR Independent) and Vit E Prevented $\mathrm{H}_{2} \mathrm{O}_{2}$-Induced ROS in Neuro2a and $\mathrm{C} 6$ Cells}

A comparison of intracellular ROS levels in Neuro2a $\left(F_{(9,70)}=7.60, p<0.001\right)$ and C6 $\left(F_{(9,70)}=6.43, p<0.001\right)$ upon various treatment-groups showed an overall significant 
A Neuro2a cell viability

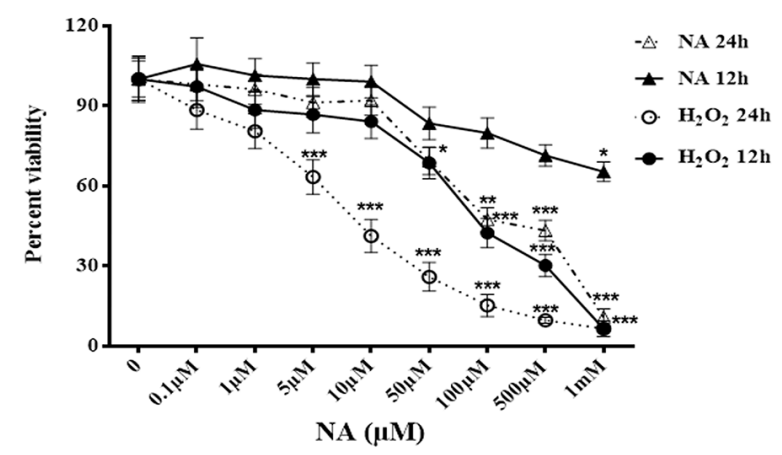

B C6 cell viability

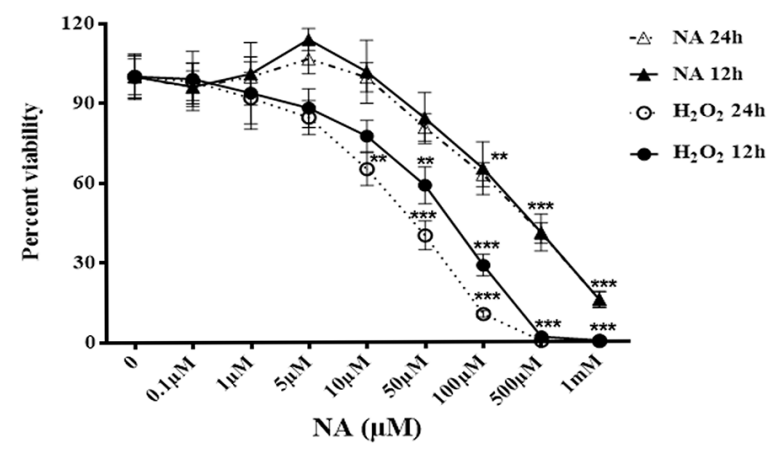

C Cell morphology

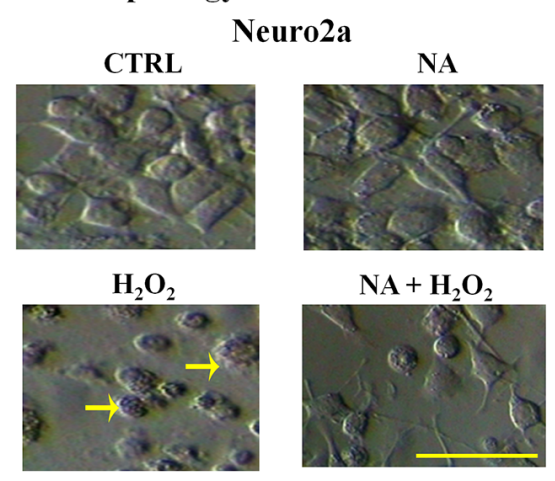

C6
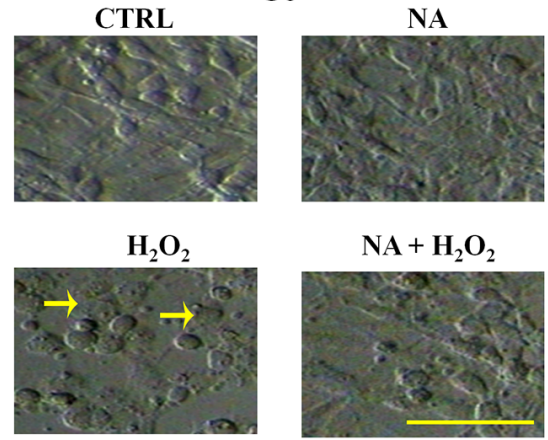

FIGURE 3 | Percentage changes in Neuro2a- and C6-cell viability after $12 \mathrm{~h}$ and $24 \mathrm{~h}$ treatment with different doses of $\mathrm{NA}_{\text {and }} \mathrm{H}_{2} \mathrm{O}_{2}$ are shown. Viability of both Neuro2a (A) and C6 (B) was least affected ( $<15 \%$ of control) by treatment with up to $10 \mu \mathrm{M}$ of NA, whereas $\mathrm{H}_{2} \mathrm{O}_{2}$ affected the cell viability in even much lesser concentration. ${ }^{*} p<0.05,{ }^{* *} p<0.01,{ }^{* * *} p<0.001$ as compared to control. Abbreviations are as in the text. (C) Representative microscopic fields of images of Neuro2a and C6 cells with or without treatment with NA $(10 \mu \mathrm{M}), \mathrm{H}_{2} \mathrm{O}_{2}$ or their combination are shown. Both Neuro2a as well as C6 cells showed less adherence to the petri-dish. Those remained adhered, showed membrane granulation and more circular (marked by arrows as representative), which are signs of cellular stress/damage or approaching death upon $\mathrm{H}_{2} \mathrm{O}_{2}$ treatment for $24 \mathrm{~h}$. Cells treated with $\mathrm{H}_{2} \mathrm{O}_{2}$ in presence of $\mathrm{NA}$ showed reduced -detachment, -granulation and -circular shaped in addition to lesser death. Scale bar $100 \mu \mathrm{m}$.

difference (Figures 4C,D). In pairwise comparison with respective control cells, $\mathrm{H}_{2} \mathrm{O}_{2}$ significantly increased ROS levels in both, Neuro2a $(p<0.001)$ and C6 $(p<0.001)$ cells, which were prevented if the cells were pre-treated with $10 \mu \mathrm{M}$ NA or Vit E (Figures 4C,D). Neither PRZ nor PRP (AR-antagonists) prevented the effect of NA. Therefore, as an alternate hypothesis, we investigated the possible involvement of iron on NA-mediated changes in ROS level.

\section{NA, Vit E, and DFX (Iron Chelator) Prevented $\mathrm{H}_{2} \mathrm{O}_{2}$-Induced ROS in Synaptosomes Prepared From Normal Rat Brain}

The ROS levels in synaptosomes, upon various treatments in the presence and absence of DFX, showed a significant $\left(F_{(7,48)}=11.98, p<0.001\right)$ difference as a group. A pairwise comparison showed that, as compared to the untreated control, although DFX $\left(\mathrm{Fe}^{3+}\right.$ chelator) decreased synaptosomal ROS levels, it did not reach a statistical significance level (Table 1). However, DFX pre-treatment significantly $(p<0.02)$ reduced
$\mathrm{H}_{2} \mathrm{O}_{2}$-induced ROS, which suggests that DFX $\left(\mathrm{Fe}^{3+}\right.$ chelator) prevented the $\mathrm{H}_{2} \mathrm{O}_{2}$-induced generation of ROS. Independently, NA $(p<0.001)$ and Vit E $(p<0.001)$ significantly attenuated the ROS levels in synaptosomes treated with $\mathrm{H}_{2} \mathrm{O}_{2}$ alone. As mentioned above, DFX alone reduced ROS generation, which was further reduced by NA as well as Vit E. Although Vit $\mathrm{C}$ potentiated $\mathrm{H}_{2} \mathrm{O}_{2}$-induced increased ROS levels (reported above), it was prevented in the presence of DFX, and the effect was further reduced in the presence of NA (Table 1).

\section{NA, Vit E and DFX (Iron Chelator) Prevented $\mathrm{H}_{2} \mathrm{O}_{2}$-Induced ROS in Neuro2a and $\mathrm{C} 6$ Cells}

A comparison of ROS values as a whole among the groups of control and NA-, DFX- and $\mathrm{Fe}^{2+}$-treated Neuro2a $\left(F_{(11,71)}=43.86, p<0.001\right)$ and C6 $\left(F_{(11,71)}=42.40, p<0.001\right)$ cells showed a significant difference. A pairwise comparison showed that neither DFX nor $\mathrm{Fe}^{2+}$ significantly affected ROS in Neuro2a or C6 cells; however, $\mathrm{H}_{2} \mathrm{O}_{2}$ significantly increased ROS levels in both cell lines, Neuro2a $(p<0.001)$, and C6 $(p<0.001)$. NA reduced ROS in both $\mathrm{H}_{2} \mathrm{O}_{2}$-treated as well as 


\section{Changes in LP}

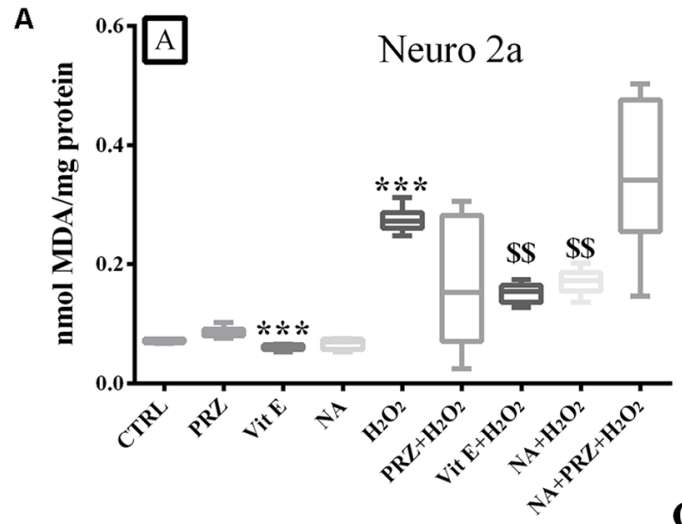

B
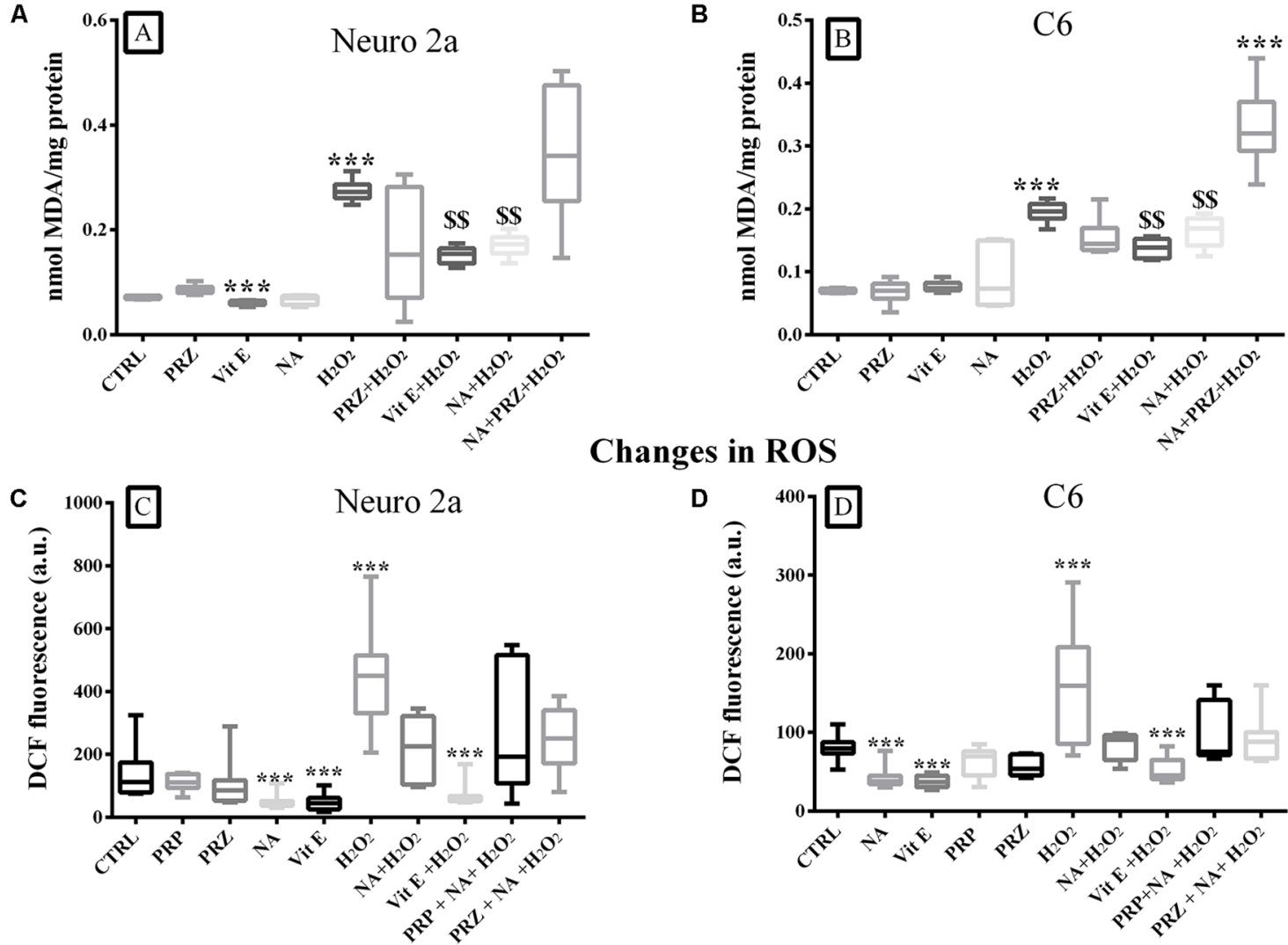

\section{Changes in ROS}

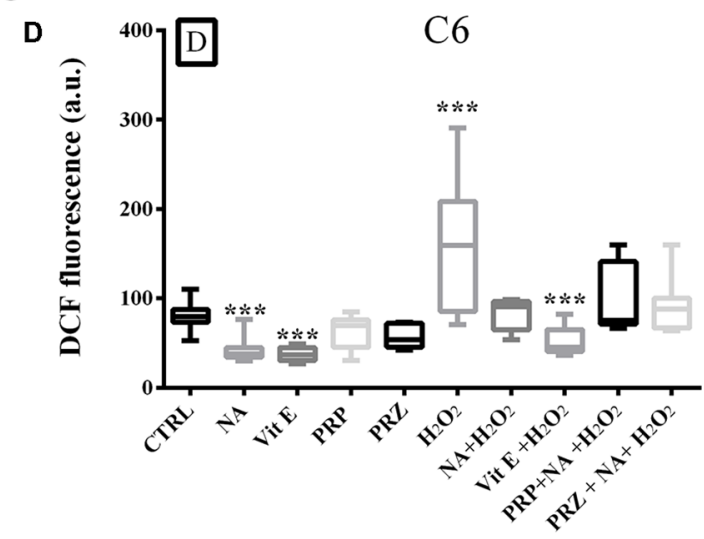

FIGURE 4 | Changes in LP (mean \pm SEM nmol of MDA) and intracellular ROS levels (as expressed by DCF fluorescence) in Neuro2a and C6 cells under control and various treatment conditions are shown as box-plots. Confluent cell culture containing about $2 \times 10^{7}$ cells grown in $100 \mathrm{~mm}$ petri dishes were treated with Vit $\mathrm{E}$, NA $(10 \mu \mathrm{M}), \mathrm{PRZ}, \mathrm{H}_{2} \mathrm{O}_{2}$ alone or in combinations (as shown in respective bars). Vit $\mathrm{E}$ (except in Neuro2a), NA and PRZ alone were by and large ineffective in modulating the LP. $\mathrm{H}_{2} \mathrm{O}_{2}$ induced increased LP was reduced by NA and Vit $\mathrm{E}$ in both Neuro2a (A) and C6 (B). The protective effect of NA on $\mathrm{H}_{2} \mathrm{O}_{2}$ induced $L P$ was lost in presence of PRZ. As shown in (C,D) in both Neuro2a and C6 respectively, ROS was increased by $\mathrm{H}_{2} \mathrm{O}_{2}$, while it was decreased by $\mathrm{NA}$ and $\mathrm{Vit} E$. The $\mathrm{H}_{2} \mathrm{O}_{2}$ induced effects were prevented by NA and Vit $\mathrm{E}$. As the NA induced effects were not prevented by AR antagonists, PRZ or PRP, it suggested that the effects were not mediated through (ARs). ${ }^{* * *} p<0.001$ as compared to untreated control and ${ }^{\$ \$} p<0.01$ in comparison with $\mathrm{H}_{2} \mathrm{O}_{2}$ treated cells. $N=4$ sets of experiments triplicate readings of $\times 10^{5}$ cells for ROS. Abbreviation as in the text.

TABLE 1 | Modulation of ROS levels in synaptosomes by $\mathrm{H}_{2} \mathrm{O}_{2}$ with or without treatment of $\mathrm{NA}$ in presence or absence of $\mathrm{Fe}^{2+}$.

\begin{tabular}{lc}
\hline Groups/conditions & $\begin{array}{c}\text { ROS (Fluorescence } \\
\text { a.u.; Mean } \pm \text { SEM) }\end{array}$ \\
\hline CTRL & $75.11 \pm 3.58$ \\
DFX $10 \mu \mathrm{M}$ & $66.46 \pm 3.37$ \\
$\mathrm{H}_{2} \mathrm{O}_{2} 100 \mu \mathrm{M}$ & $102.56 \pm 2.04^{* * *}$ \\
DFX $10 \mu \mathrm{M}+\mathrm{H}_{2} \mathrm{O}_{2} 100 \mu \mathrm{M}$ & $75.68 \pm 4.16$ \\
DFX $10 \mu \mathrm{M}+\mathrm{NA} 100 \mu \mathrm{M}+\mathrm{H}_{2} \mathrm{O}_{2} 100 \mu \mathrm{M}$ & $49.10 \pm 9.05^{*}$ \\
DFX $10 \mu \mathrm{M}+\mathrm{Vit} \mathrm{E} 100 \mu \mathrm{M}+\mathrm{H}_{2} \mathrm{O}_{2} 100 \mu \mathrm{M}$ & $55.89 \pm 4.61^{* *}$ \\
DFX $10 \mu \mathrm{M}+\mathrm{Vit} \mathrm{C} 100 \mu \mathrm{M}+\mathrm{H}_{2} \mathrm{O}_{2} 100 \mu \mathrm{M}$ & $65.06 \pm 8.39$ \\
DFX $10 \mu \mathrm{M}+\mathrm{NA} 100 \mu \mathrm{M}+\mathrm{Vit} \mathrm{C} 100 \mu \mathrm{M}+\mathrm{H}_{2} \mathrm{O}_{2} 100 \mu \mathrm{M}$ & $40.92 \pm 4.68^{* * *}$ \\
\hline
\end{tabular}

$\mathrm{H}_{2} \mathrm{O}_{2}$ induced an increase in $\mathrm{ROS}$, while chelation of iron in the presence of DFX blocked the $\mathrm{H}_{2} \mathrm{O}_{2}$ induced $\mathrm{ROS}$ generations. Treatment of NA led to additional decrease in ROS levels in DFX treated cells. Either Vit $E$ or Vit $C$ did not affect the $\mathrm{H}_{2} \mathrm{O}_{2}$ induced $\mathrm{ROS}$ production. $n=7,{ }^{*} p<0.05,{ }^{* *} p<0.01,{ }^{* * *} p<0.001$ compared to untreated control (CTRL), abbreviations as in text.

normal cells. Further, in Neuro2a and C6 cells, $\mathrm{Fe}^{2+}\left(\mathrm{FeSO}_{4}\right)$ and $\mathrm{H}_{2} \mathrm{O}_{2}$ together significantly $(p<0.001)$ increased ROS levels and NA prevented the effects. The prevention of $\mathrm{Fe}^{2+}$ and $\mathrm{H}_{2} \mathrm{O}_{2}$-induced ROS generation by NA and DFX was comparable (Figures 5A,B).

\section{NA inhibited $\mathrm{Fe}^{2+}-\mathrm{Fz}$ Complex Formation}

To confirm the findings reported above, we needed to show if NA could chelate/bind $\mathrm{Fe}^{2+}$. FZ is known to selectively chelate $\mathrm{Fe}^{2+}$ and the chelated complex can be detected by specific absorbance at $562 \mathrm{~nm}$ (Stookey, 1970). On incubating an increasing concentration of $\mathrm{FeSO}_{4}(5-50 \mu \mathrm{M})$ with $\mathrm{FZ}$ in vitro, there was a dose-dependent increase in absorbance of $\mathrm{Fe}^{2+}-\mathrm{FZ}$ complex (Figure 6). However, when $\mathrm{FeSO}_{4}$ was pre-incubated with varying concentrations of NA $(10-100 \mu \mathrm{M})$ before treating with FZ, there was a dose-dependent decrease in the absorbance as compared to without the treatment of NA (Figure 6A). Still, a higher dose of NA was not tried as the absorbance reached almost zero. To rule out any confounds due to $\mathrm{Fe}^{3+}$, we replaced $\mathrm{FeSO}_{4}$ with $\mathrm{FeCl}_{3}(5-50 \mu \mathrm{M})$ and treated with $\mathrm{FZ}$, which gave 


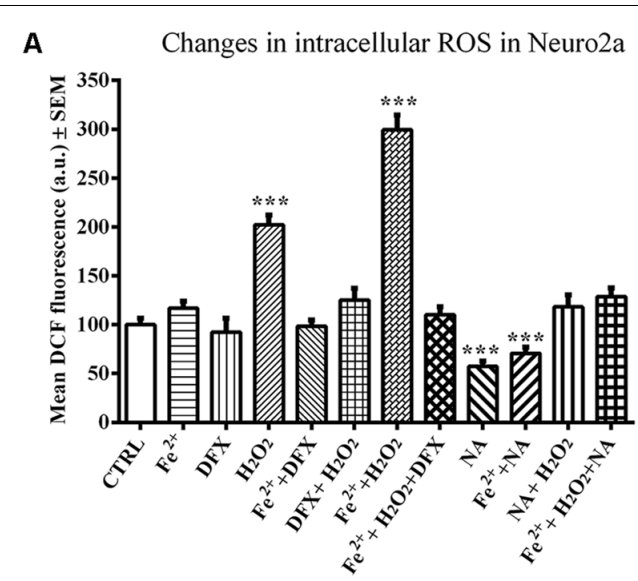

B

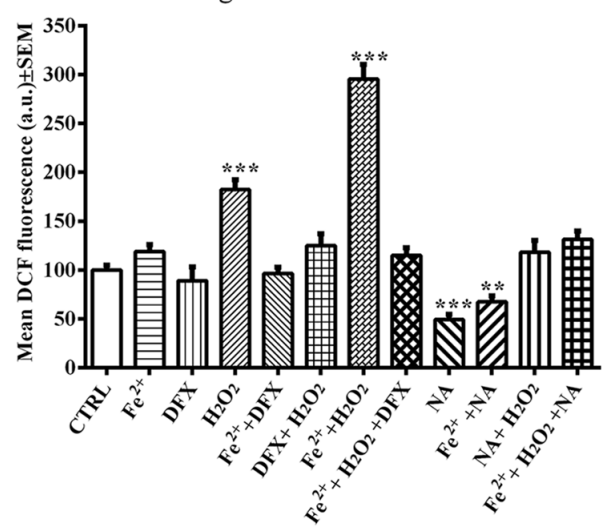

FIGURE 5 | NA mediated modulation of intracellular ROS levels in presence of iron in Neuro2a (A) and C6 (B) is shown. $2 \times 10^{5}$ cells per well were seeded in 96 well plates and incubated for $12 \mathrm{~h}$ in serum free medium lacking iron or in medium containing $10 \mu \mathrm{M} \mathrm{FeSO}$ as source of iron $\left(\mathrm{Fe}^{2+}\right)$. Cells in both the media were treated with $\mathrm{H}_{2} \mathrm{O}_{2}$ alone or in presence of NA or DFX for $2 \mathrm{~h}$. At the end the cells were incubated with medium containing $25 \mu \mathrm{M}$ DCFDA for 30 min followed by PBS washing and DCF fluorescence estimation. In the presence of $\mathrm{Fe}^{2+}, \mathrm{H}_{2} \mathrm{O}_{2}$ enhanced ROS generation in both the cells, Neuro2a (A) and C6 (B), which were prevented by DFX and NA. ${ }^{* *} p<0.01,{ }^{* * *} p<0.001$ as compared with control. Abbreviations are in the text.

negligible absorbance (Figure 6B). Taken together, all these observations suggested that NA chelated $\mathrm{Fe}^{2+}$ that reduced $\mathrm{Fe}^{2+}$ FZ complex formation.

\section{NA Protected Neuro2a and C6 Cell Death by Reducing ROS}

We have seen above that NA reduced the ROS level in Neuro2a and C6. Although reduced ROS is an indicator of prevention or protection from cell death, we confirmed it qualitatively as well as quantitatively using three methods. First, we cultured Neuro2a and C6 cells on coverslips as well as in cell culture plates and treated them for $2 \mathrm{~h}$ (for ROS estimation) or $24 \mathrm{~h}$ (for evaluation of cell death) with $\mathrm{H}_{2} \mathrm{O}_{2}$ alone or in the presence of NA. Intracellular ROS profile can be seen in photomicrographs (Figures 7A,E). As compared to untreated control cells, $\mathrm{H}_{2} \mathrm{O}_{2}$ significantly $(p<0.001)$ increased ROS levels in both types of cells, which were almost completely prevented

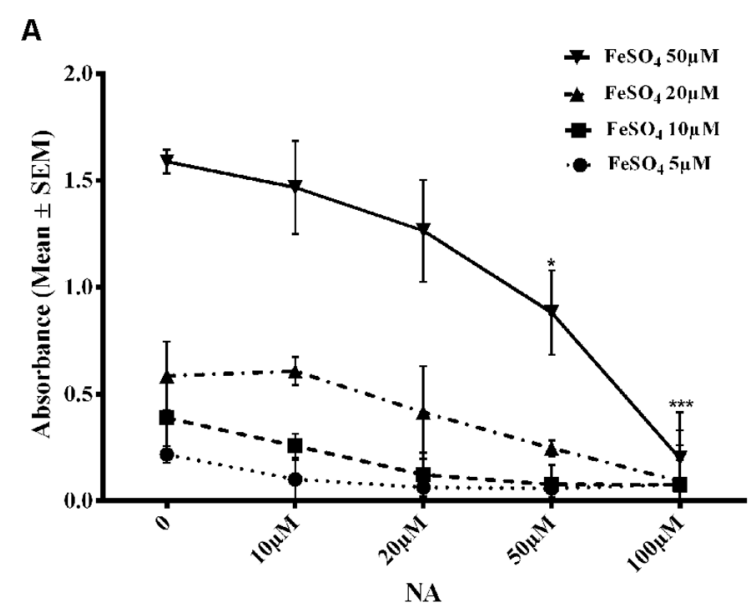

B

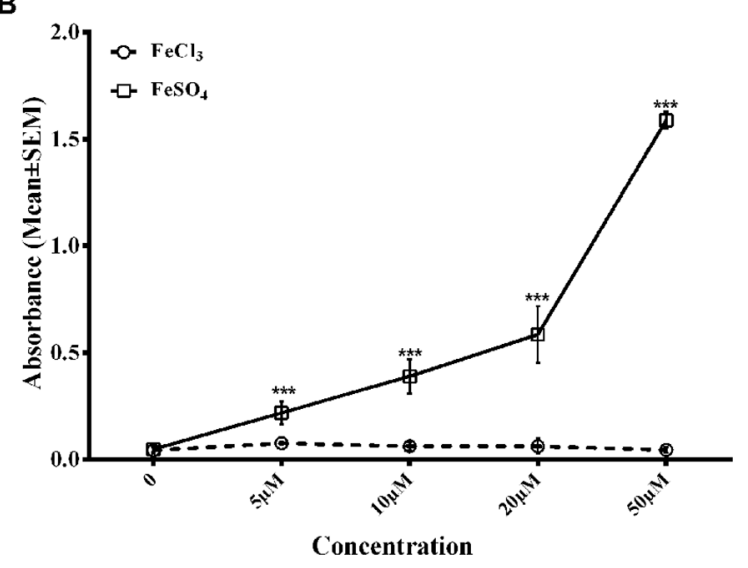

FIGURE 6 | Dose response of NA on reduction in Fe-FZ complex formation is shown. Absorbance of Fe-FZ decreased with addition of increased dose of NA (A). FZ selectively binds to $\mathrm{Fe}^{2+}$ and not to $\mathrm{Fe}^{3+}$ as shown by increased absorbance in presence of $\mathrm{FeSO}_{4}$ and not in the presence of $\mathrm{FeCl}_{3}$ (B). The results suggest the $\mathrm{Fe}^{2+}$-chelating ability of $\mathrm{NA} .{ }^{*} p<0.05,{ }^{* * *} p<0.001$ as compared to control. Abbreviations are as in the text.

by NA (Figures 7B,F). Second, by PI staining qualitatively, it was observed in coverslip-grown cells that NA provided protection to both the cells and prevented $\mathrm{H}_{2} \mathrm{O}_{2}$-induced death (Figures 7D,H). Although PI stained dead cells grown on coverslip could have been quantified, we argued that as the dead cells would tend to detach from the coverslips, the results could be less accurate. To address this issue and to obtain relatively more accurate results particularly in our study we used an additional third method, the trypan-blue assay, to quantify the NA-induced protection of cells. In this method, dead Neuro2a and C6 cells were counted upon treatment with $\mathrm{H}_{2} \mathrm{O}_{2}$ in the presence and absence of $10 \mu \mathrm{M} N$, as described in the "Materials and Methods" section. We observed that as compared to untreated control cells, $\mathrm{H}_{2} \mathrm{O}_{2}$ significantly increased the death of Neuro2a $(p<0.001)$ as well as C6 $(p<0.001)$ cells. Further, as compared with cells treated with $\mathrm{H}_{2} \mathrm{O}_{2}$ alone, the cell death was significantly $(p<0.01$ for both Neuro2a as well as C6) reduced when they were treated with $\mathrm{H}_{2} \mathrm{O}_{2}$ in the 
A

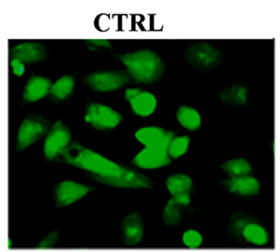

$\mathrm{H}_{2} \mathrm{O}$
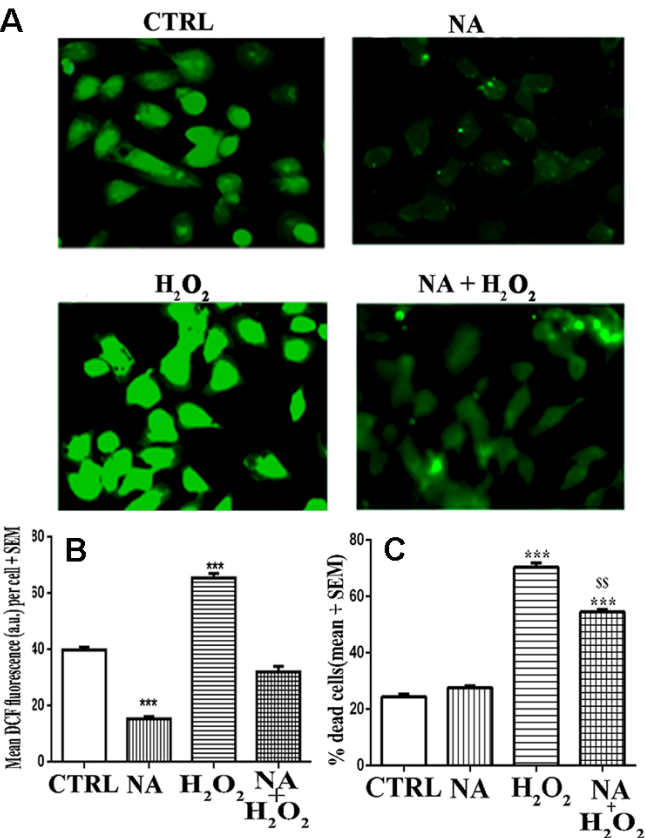

$\mathrm{NA}+\mathrm{H}_{2} \mathrm{O}$

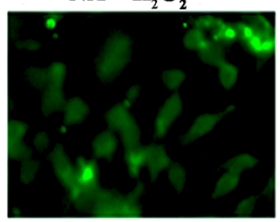

Neuro2a

D

DAP

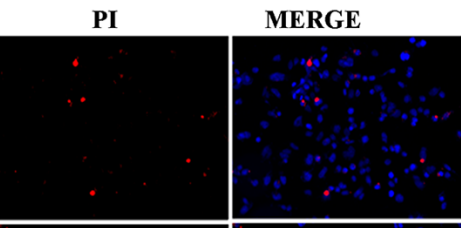

$\vec{\partial}$
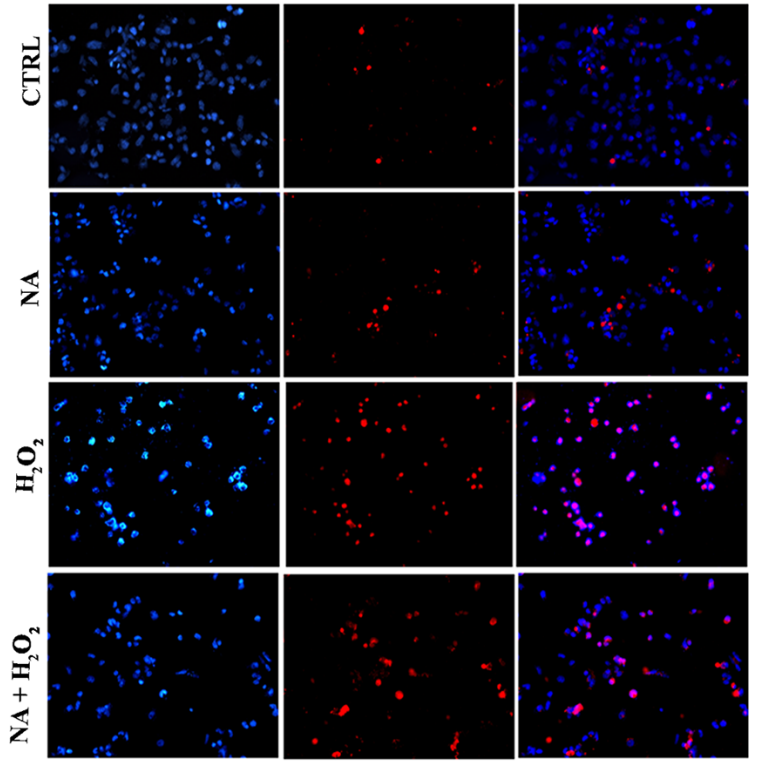

E

CTRL

NA
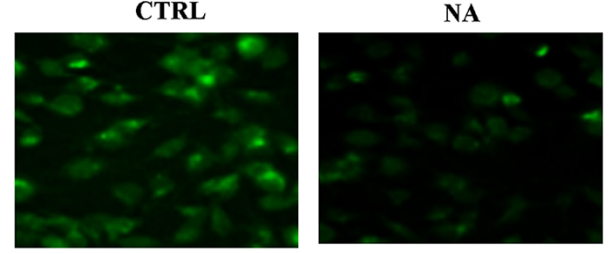

C6

\section{H}

$\mathrm{NA}+\mathrm{H}_{2} \mathrm{O}_{2}$
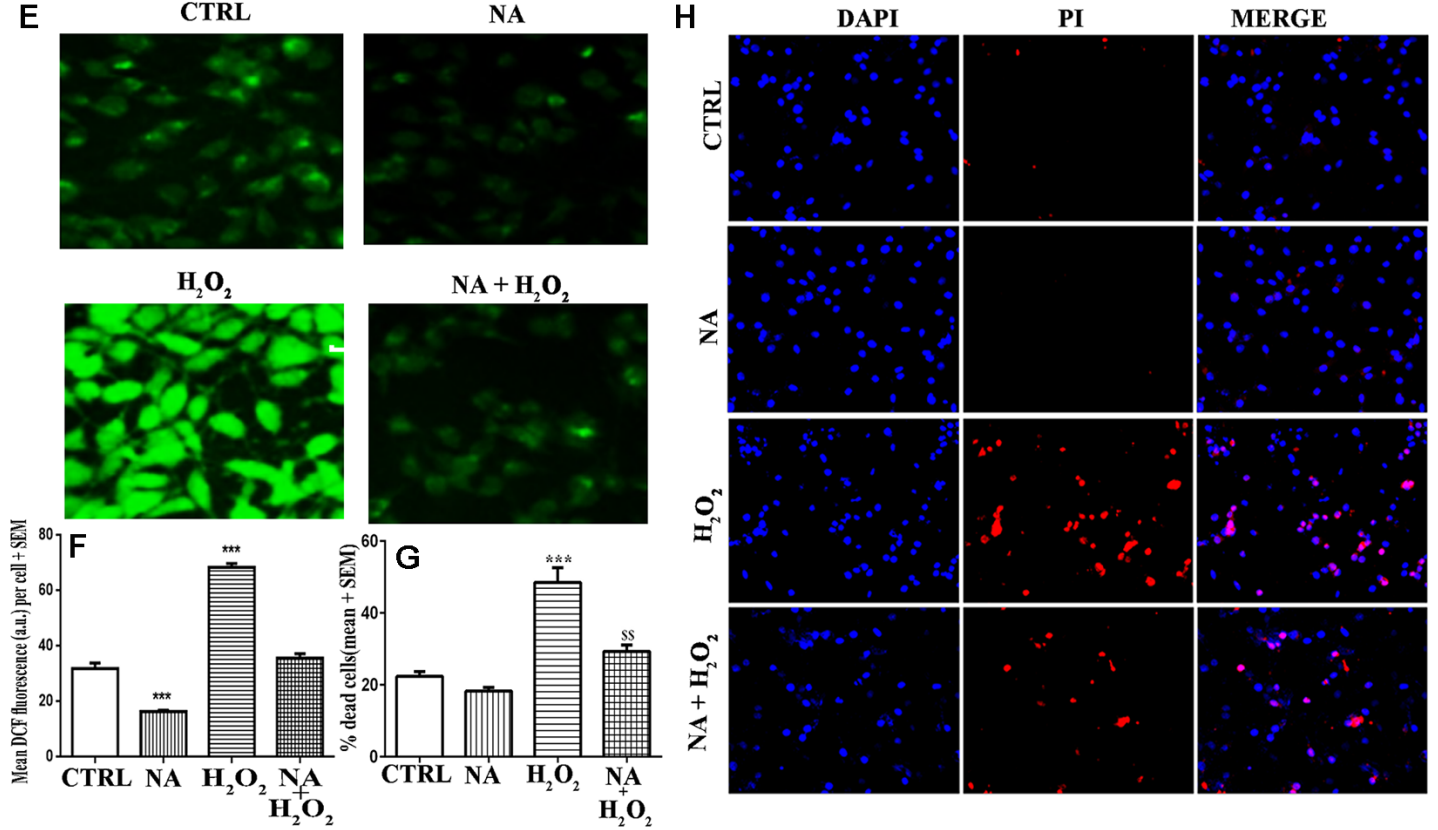

FIGURE 7 | Protective role of $\mathrm{NA}(10 \mu \mathrm{M})$ on $\mathrm{H}_{2} \mathrm{O}_{2}$-induced ROS generation and cell death in Neuro2a (upper panels, A-D) and C6 (lower panels, E-H) is shown. Representative photomicrographs of intracellular DCF fluorescence indicative of ROS levels in Neuro2a (A) and C6 (E) are shown. Cells treated with $\mathrm{H}_{2} \mathrm{O}_{2}$ alone showed significantly higher fluorescence per cell, while $\mathrm{NA}$ treated cells showed significantly reduced fluorescence per cell upon $\mathrm{H}_{2} \mathrm{O}_{2}$ treatment. Corresponding histograms of relative fluorescence intensities per cell (mean of 500-600 cells per treatment) from five sets of experiments of Neuro2a (B) and C6 (F) are shown. In separate sets of experiments, the cells were treated for $24 \mathrm{~h}$ and percent dead cells were quantified using trypan blue assay. $\mathrm{H}_{2} \mathrm{O}_{2}$ significantly increased cell death, which was protected in presence of NA for Neuro2a (C) and C6 (G). Also, using DAPI (stains all live and dead cells) and PI (stains only dead cells) the proportion of dead cells were quantified in coverslip-grown cells treated with $\mathrm{NA}, \mathrm{H}_{2} \mathrm{O}_{2}$ or both together. Significantly more number of nuclei were PI (red) stained by treatment of $\mathrm{H}_{2} \mathrm{O}_{2}$ alone as compared to $\mathrm{NA}$ alone and $\mathrm{NA}+\mathrm{H}_{2} \mathrm{O}_{2}$. Representative photomicrographs (20X) of DAPI and PI stained Neuro2a (D) and C6 (H) are shown. PI stained cell shown in red are dead while DAPI stained all nuclei irrespective of live or dead are shown in blue; $\mathrm{PI}$ stained cells are seen more in $\mathrm{H}_{2} \mathrm{O}_{2}$ treated groups. All readings were taken in duplicate and three $(N=3)$ such sets of experiments were conducted. ${ }^{* * *} p<0.001$ as compared to untreated cells, while $\$ \$ p<0.01$ as compared to $\mathrm{H}_{2} \mathrm{O}_{2}$ treated cells. Abbreviations are as in the text. 
presence of $10 \mu \mathrm{M}$ NA (Figures 7C,G); the findings confirmed our contention as a proof-of-principle that NA protected the Neuro2a and C6 cells from ROS-induced oxidative damage and death. However, although the cell death by $\mathrm{H}_{2} \mathrm{O}_{2}$ in the presence of NA was significantly lower than treatment with $\mathrm{H}_{2} \mathrm{O}_{2}$ alone, it was higher than the untreated controls, which may appear deceptive. To explain, we argue that complete protection would depend on many contributory factors, including dose and duration of exposure of cells to $\mathrm{NA}$ and $\mathrm{H}_{2} \mathrm{O}_{2}$, age and sensitivity of the cells, oxidative inactivation, and the metabolism of NA.

\section{Dual Response of NA on ROS Generation in 66 Cells}

In the cell death assay (above), it was observed that $10 \mu \mathrm{M}$ NA provided incomplete protection of the cells. Therefore, we evaluated the level of ROS generation in C6 cells treated with four doses $(5,10,50$ and $100 \mu \mathrm{M})$ of NA alone. We used one of the cells lines (C6 in this case) as a proof-of-principle; synaptosomes were not used as they are non-living. As compared to non-NA treated control cells, the lower doses of NA (5 and $10 \mu \mathrm{M})$ were significantly reduced $(p<0.001$ at $10 \mu \mathrm{M})$, while higher doses significantly increased $[50 \mu \mathrm{M}(p<0.05)$ and $100 \mu \mathrm{M}(p<0.001)]$ intracellular ROS (fluorescence) levels (Figure 8). This indicated that a lower concentration of NA protected the cells, while a higher concentration failed to protect the cells from ROS accumulation, which would be damaging to the cells.

\section{DISCUSSION}

Living tissues routinely carry out metabolic processes, resulting in the continuous generation of ROS as a by-product (Seaver and Imlay, 2004). ROS, being highly reactive, triggers cascading effects, including the induction of LP (Leutner et al., 2001), protein and DNA damage (Valko et al., 2004; Galli et al., 2005), leading to neuronal loss (Casadesus et al., 2004). The vulnerability of the brain to such oxidative damage increases

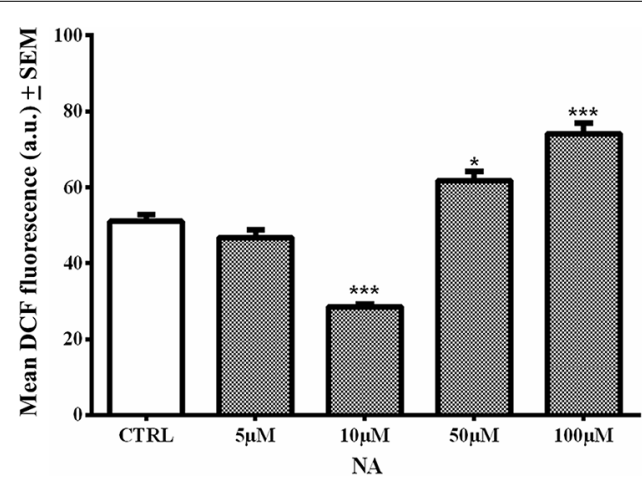

FIGURE 8 | Dose response of NA on ROS generation in C6 cells is shown. At lower concentration (10 $\mu \mathrm{M}) \mathrm{NA}$ reduced ROS levels, while at higher concentration $(100 \mu \mathrm{M})$ there was significant increase in intracellular ROS and it was damaging. ${ }^{*} p<0.05$ and ${ }^{* * *} p<0.001$ in comparison to untreated controls. logarithmically because of several reasons including on one hand, the fact that it possesses a large quantity of polyunsaturated fatty acids (the substrate for ROS generation) and it is rich in iron (which favors the Fenton reaction and ROS generation), and on the other hand, it contains significantly less antioxidants to scavenge the continuously generated ROS. It is possible that to compensate at least partially, the brain has been gifted with a natural protector, the NA, possessing antioxidant property (Troadec et al., 2001; Traver et al., 2005). Therefore, we investigated in vivo and in vitro NA-ergic modulation of LP and ROS levels with and without the involvement of ARs and the role of iron. Also, we investigated the effect of NA because its level changes with a unique physiological process regulated by the brain, the REMS and its loss (Mallick et al., 2002, 2012). The results of our in vitro studies including those on cell-lines, complement the findings from in vivo animal studies. They suggest that low level of NA protects the brain (neurons and glia) from oxidative insult by reducing LP and ROS, while a high level of NA-induced cell death.

In this study, we observed that both LP and ROS decreased in synaptosomes prepared from REMS-deprived rat brains. PRZ, by binding on the post-synaptic alpha1-AR, prevented the released NA to induce its action (Greengrass and Bremner, 1979), while CLN, by acting on the pre-synaptic alpha2$\mathrm{AR}$, inhibited the release of NA (Washburn and Moises, 1989; Tomasini et al., 1992; Wang et al., 2017); thus, the resultant effect of both PRZ and CLN was similar although the mechanism of action differed. A closer evaluation of the results, particularly with PRZ and CLN, suggest that the NA-induced effect on LP was AR-mediated, while the effect on ROS was both AR and non-AR mediated; the latter effect could be due to the antioxidant property of NA. To understand the complex mechanism of action, as a first step, in the cell-culture model we used $\mathrm{H}_{2} \mathrm{O}_{2}$ to induce ROS and LP within live cells. The $\mathrm{H}_{2} \mathrm{O}_{2}$ was chosen as it is membrane permeable, endogenously produced as well as metabolized, it is known to induce ROS and its associated cellular consequences (Antunes and Cadenas, 2000; Ullrich and Kissner, 2006). The $\mathrm{H}_{2} \mathrm{O}_{2}$-induced enhanced ROS and LP productions were prevented by NA, which supported the antioxidant property of the latter.

Vit E, Vit C and glutathione scavenge free radicals and ROS to protect tissues from oxidative damage. We compared the effects of NA, Vit E, and Vit $\mathrm{C}$ on $\mathrm{H}_{2} \mathrm{O}_{2}$-induced ROS generation. Vit $\mathrm{E}$ is a potent antioxidant (Koul et al., 2005; Singh et al., 2005), while Vit C is reported to behave as proas well as anti-oxidant (Halliwell, 1996; Carr and Frei, 1999). We observed that in the absence of $\mathrm{H}_{2} \mathrm{O}_{2}$, Vit $\mathrm{E}$ decreased ROS levels in synaptosomes similar to that of NA; while Vit C induced opposite effects. Further, both NA and Vit E individually as well as together prevented the $\mathrm{H}_{2} \mathrm{O}_{2}$-induced increase in ROS levels, while Vit $\mathrm{C}$ potentiated the $\mathrm{H}_{2} \mathrm{O}_{2}$ effects. These findings, however, suggest that NA apparently acts analogously to that of Vit $\mathrm{E}$ to decrease ROS, the precise mechanism of action needed elaborate study. It is generally known that NA as neurotransmitter usually acts through ARs. Although 
non-AR mediated action of NA has been proposed infrequently, its mechanism of action particularly in vivo and its relation with REMS were unknown, which has been confirmed in this study.

The brain is rich in the essential nutrient, iron, which facilitates generation of ROS through Fenton reaction (Haber and Weiss, 1932); therefore, an optimum level of iron is necessary for maintaining normal physiological processes. An elevated iron is associated with neuro-degenerative diseases (Castellani et al., 2004; Zecca et al., 2004), while iron deficiency including anemia is associated with restless leg syndrome (Lee et al., 2001; Allen and Earley, 2007; Patrick, 2007; Auerbach, 2014; Connor et al., 2017); interestingly, in all those diseases, REMS is adversely affected. As REMS maintains brain NA level (Mallick and Singh, 2011; Mehta et al., 2017) and the latter possesses catechol ring that can chelate iron, we explored the relationship between NA and iron levels in modulating ROS in the brain, importantly an antioxidant compromised organ.

As iron exists in the body in $\mathrm{Fe}^{3+}$ and $\mathrm{Fe}^{2+}$ forms, we explored their specificity in providing protection to the brain from oxidative insult (as evidenced by ROS generation). Either DFX, a specific $\mathrm{Fe}^{3+}$ chelator or NA and their combination not only reduced ROS level, they also prevented the potentiation of ROS formation by $\mathrm{H}_{2} \mathrm{O}_{2}$ in synaptosomes. Subsequently, we confirmed the findings on Neuro2a and C6 (living) cells, which have been routinely used as models for understanding neuronaland glial-cellular physiology, respectively. We observed that $\mathrm{H}_{2} \mathrm{O}_{2}$-induced LP and ROS levels were prevented by NA and Vit E. Further, as the protective effect of NA was comparable in synaptosomes and in cultured (living) cells, it is expected that a similar mechanism operates in the brain in vivo as well; however, this needs to be confirmed. Thereafter, we embarked on understanding the involvement of $\mathrm{Fe}^{2+}$ and the mechanism of action of NA in providing the protection. We demonstrated that the $\mathrm{Fe}^{2+}$ enhanced $\mathrm{H}_{2} \mathrm{O}_{2}$-induced ROS generation in both, Neuro2a and C6 cells and the effect was prevented by NA and DFX, possibly by the chelation of iron $\left(\mathrm{Fe}^{2+} / \mathrm{Fe}^{3+}\right)$ in the medium, as classically the latter is known to chelate $\mathrm{Fe}^{3+}$.

By estimating the Fe-FZ complex, we confirmed that NA chelated $\mathrm{Fe}^{2+}$ (not $\mathrm{Fe}^{3+}$ ) and prevented the Fenton reaction from inducing ROS even in the presence of $\mathrm{H}_{2} \mathrm{O}_{2}$ and thus, the oxidative load of the cells was reduced. This finding may be supported by an earlier report that amines including NA possesses a divalent ion-chelating property (García et al., 2012). It may be argued that isolated, scattered report (Andersson et al., 1988) has shown possible indirect interaction between $\mathrm{Fe}^{3+}$ and NA under a certain specific condition and that might influence the findings. However, in our experimental condition such interaction is an unlikely possibility and may need to be confirmed. Finally, to confirm if our proposed mechanism really works to prevent cell-death, we treated cultured Neuro2a and $\mathrm{C} 6$ cells with $\mathrm{H}_{2} \mathrm{O}_{2}$ in the presence and absence of NA and quantified dead/live cells. We observed that the presence of NA indeed reduced ROS as well as cell-death induced by $\mathrm{H}_{2} \mathrm{O}_{2}$ alone (Figure 7). Although this observation supported our contention as a proof-of-principle that NA protected the cells from the oxidative burden and cell death, one may argue that the protection was incomplete. We argue that as a living system is exposed to multiple opposing metabolic modulators, total protection could possibly be obtained by varying one or more factors e.g., the dose, duration of exposure and oxidation level of NA, the metabolic state, sensitivity, age and predisposition of the cells and other non-specific factor(s) in the cellular milieu, which was not the primary aim of this study and needs to be investigated.

Therefore, we further evaluated the dose response of NA on normal ROS generation in C6 cells. A lower dose $(\simeq 10 \mu \mathrm{M})$ of NA prevented, while a higher dose $(\simeq 100 \mu \mathrm{M})$ failed to prevent the elevation of ROS as compared to normal conditions in the C6 cells. The dual response of NA on ROS generation was dependent on the concentration of the compound and may be supported by C6 viability (Figure 3B). Further, as a critical evaluation we should mention that in our study with synaptosomes (Figures 2, 3 and Table 1), $100 \mu \mathrm{M}$ of NA (the dose was selected to start with based on our previous report with synaptosomes) reduced ROS generation in synaptosomes, which may deceptively appear to be non-supportive. The reasons could be that: (i) earlier we did not carry out dose response of NA on synaptosomes; and (ii) as compared to living cells, the synaptosomes differ in their -milieu, -metabolism, -oxidation/ reduction levels and-dynamicity. For living cells, although the precise protective concentration of NA may not be readily predicted, our findings support, in principle, that at least a lower dose of NA reduces the ROS level and provides protection to the brain, while a higher dose including upon REMSD, is destructive; the latter even in vivo has been reported to act through alpha-ARs (Biswas et al., 2006; Ranjan et al., 2010; Somarajan et al., 2016).

We used the flower-pot method, the most practical and globally preferred method of choice for long-term REMSD with least human intervention. The arguments offered in favor of the observed effects being specific to REMSD (Vogel, 1975; Gulyani et al., 2000; Mehta et al., 2018) hold true for this study also. Further, the observed effects were due to REMSD because the changes returned to normal level in the REC rats. To rule out unavoidable, undesirable, confounding non-specific effects including some loss of non-REMS and stress, if at all, we carried out LPC group (control). The LPC and REMSD rats suffer comparable non-specific influence and the former suffer a non-significant loss of REMS, particularly when maintained on the large platform for longer than $48 \mathrm{~h}$ (Mendelson et al., 1974). As LP and ROS in LPC and FMC rats were comparable, while the effects in experimental rats were significantly different, the effects of non-specific factors on REMSD rats can be safely ruled out. Notwithstanding this, a few isolated conflicting findings have been reported e.g., one study showed no change (D’Almeida et al., 1997), while another showed a higher level (Mathangi et al., 2012) of LP upon REMSD. The differences in results are likely due to non-compliance with animal-weight to the platform-size ratio as has already been reported (Mehta et al., 2018). A specific ratio of body weight to platform size is of critical importance for inducing REMSD to the experimental animals and for the LPC animals to serve as 
an ideal control (Yanik and Radulovacki, 1987); hence, the results of the two studies cannot be compared. Besides, our contention gets support by another report in which as the desired body weight to platform size ratio was maintained even for higher weight group of rats, the animals expressed reduced LP (Singh et al., 2008).

To avoid perceived possible stress, in isolated studies (Khadrawy et al., 2011; Suer et al., 2011; Zhang et al., 2013), multiple platforms were used for REMSD (unlike the single platform used in most, including this, study); however, the results were inconsistent. The differences in results could be due to the fact that the experimental protocol in those studies suffered various issues including body weight to platform size ratio, lack of adequate controls, lack of recovery group, prevention of the induced change by AR-antagonist, which have been carefully taken care of in this study to rule out non-specific effects. Also, it may be noted that unlike use of single platform used in this and our earlier studies (Das et al., 2008), where there was reduced LP, in most of the studies where multiple platforms were used (Khadrawy et al., 2011; Suer et al., 2011; Zhang et al., 2013), there have been increased LP, which needs to be carefully interpreted and investigated. One obvious reason for the difference in results is that as the animal body weight to platform size was not maintained, the LPC rats were also REMSD, thus adequate control was missing. Additionally, our yet unpublished observation that in a multiple platform method, because of the presence of more than one animal in the same enclosure, one animal jumps to anther platform where other animal rests/sleeps and thus, animals on small as well as large platforms are sleep deprived, support our contention. Finally, electrophysiological sleep-waking recordings of rats on flower-pot (as used in this study) confirmed selective REMS loss of the experimental rats and importantly, the effects were not due to stress (Porkka-Heiskanen et al., 1995; McDermott et al., 2003; Kitka et al., 2009). This supports our contention that the effects observed in this study were due to the REMSD of the rats.

\section{SUMMARY}

The brain is metabolically more active than other organs and being an antioxidant compromised organ, it is more sensitive as well as vulnerable to oxidative load. It has been reported earlier that REMSD-induced elevated NA caused apoptosis in rat brains (Biswas et al., 2006; Ranjan et al., 2010; Somarajan et al., 2016) and induced neuro-degenerative disorders (Postuma et al., 2013; Pillai and Leverenz, 2017); however, the molecular mechanism of action was unknown. On the contrary, NA is known to possess antioxidant property. Therefore, we explored the dose-dependent possible mechanism of action of NA in preventing an oxidative load induced damage to neurons and glia. As shown in Figure 1 (in vivo study), REMSD decreased ROS (and LP), which was prevented by CLN (which reduces NA release) and PRZ (which prevented NA to act on alpha1 AR). We then went on to decipher the possible mechanism of action of NA (Figure 9A), which we carried out in vitro on synaptosomes and cell lines for obvious reason that all variables cannot be

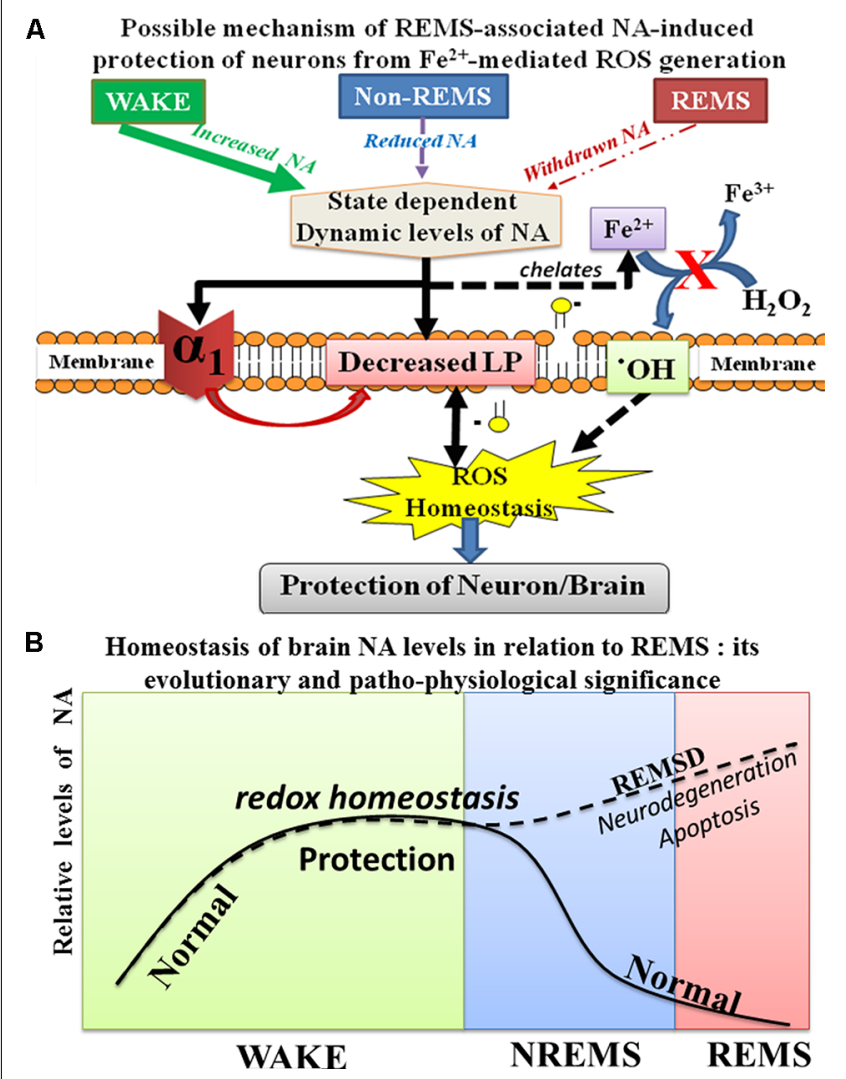

FIGURE 9 | Schematic illustration shows the possible relationship of NA-mediated neuroprotective mechanism during sleep and waking. During waking as the brain is metabolically more active, more ROS is generated; however, continuous release of NA from the NA-ergic REM-OFF neurons protects the brain from oxidative damage. NA prevents ROS generation in cells by reducing $\alpha 1-A R$ mediated reduction in LP as well as by possible chelation of $\mathrm{Fe}^{2+}$ (A). Further during REMS, NA-ergic REM-OFF neurons slow-down and stop activity resulting in washing-off the accumulated NA to maintain homeostasis and the cycle repeats $(\mathbf{B})$. Thus, the finding helps explaining role of REMS in maintaining brain NA level. Abbreviations are as in the text.

controlled in vivo. The findings of this study that a lower dose of NA prevents conversion of $\mathrm{Fe}^{3+}$ to $\mathrm{Fe}^{2+}$ and reduces ROS generation through Fenton reaction and prevents neuronal death partly help in resolving the paradox. However, further in vivo studies are needed to confirm our in vitro results and to understand why and how a higher dose of NA induces more ROS.

\section{PHYSIOLOGICAL SIGNIFICANCE AND CONCLUSION}

The findings of this study, together with our knowledge of neural regulation and function(s) of REMS (Mallick and Singh, 2011; Mallick et al., 2012), help us to conclude as follows. During the day when the brain is more active, a continuous release of NA from REM-OFF neurons inhibits the Fenton reaction to maintain the generation of ROS under control and thus, the effect of oxidative onslaught on the brain is reduced. As continuous 
activity of those NA-ergic neurons through the day tends to elevate the NA level, which would damage the neurons and glia (mechanism yet to be deciphered), the REM-OFF neurons cease activity to wash off or at least significantly reduce the level of NA in the brain and this stage is REMS. Thus, essentially, REMS maintains the NA level possibly to protect the brain. As the critical level of NA (set-point) is in dynamic equilibrium with many associated patho-physiological processes and cellular recovery, we refrain from commenting on the said set-point. Our findings are proof-of-principle that provide the basic scaffold to explain, at least partly, the molecular mechanism of REMS-associated protection of the brain, particularly involving NA (Figure 9B).

\section{DATA AVAILABILITY}

All datasets generated for this study are included in the manuscript.

\section{REFERENCES}

Allen, R. P., and Earley, C. J. (2007). The role of iron in restless legs syndrome. Mov. Disord. 22, S440-S448. doi: 10.1002/mds.21607

Andersson, K. K., Cox, D. D., Que, L. Jr., Flatmark, T., and Haavik, J. (1988). Resonance Raman studies on the blue-green-colored bovine adrenal tyrosine 3-monooxygenase (tyrosine hydroxylase). Evidence that the feedback inhibitors adrenaline and noradrenaline are coordinated to iron. J. Biol. Chem. 263, 18621-18626.

Antunes, F., and Cadenas, E. (2000). Estimation of $\mathrm{H}_{2} \mathrm{O}_{2}$ gradients across biomembranes. FEBS Lett. 475, 121-126. doi: 10.1016/s0014-5793(00)01638-0

Auerbach, M. (2014). The role of intravenous iron for the treatment of restless legs syndrome. Am. J. Hematol. 89:1016. doi: 10.1002/ajh.23820

Baskey, G., Singh, A., Sharma, R., and Mallick, B. N. (2009). REM sleep deprivation-induced noradrenaline stimulates neuronal and inhibits glial $\mathrm{Na}-\mathrm{K}$ ATPase in rat brain: in vivo and in vitro studies. Neurochem. Int. 54, 65-71. doi: 10.1016/j.neuint.2008.10.006

Biswas, S., Mishra, P., and Mallick, B. N. (2006). Increased apoptosis in rat brain after rapid eye movement sleep loss. Neuroscience 142, 315-331. doi: 10.1016/j. neuroscience.2006.06.026

Carr, A., and Frei, B. (1999). Does vitamin C act as a pro-oxidant under physiological conditions? FASEB J. 13, 1007-1024. doi: 10.1096/fasebj.13.9. 1007

Casadesus, G., Smith, M. A., Zhu, X., Aliev, G., Cash, A. D., Honda, K., et al. (2004). Alzheimer disease: evidence for a central pathogenic role of iron-mediated reactive oxygen species. J. Alzheimers Dis. 6, 165-169. doi: 10.3233/jad-20046208

Castellani, R. J., Honda, K., Zhu, X., Cash, A. D., Nunomura, A., Perry, G., et al. (2004). Contribution of redox-active iron and copper to oxidative damage in Alzheimer disease. Ageing Res. Rev. 3, 319-326. doi: 10.1016/j.arr.2004.01.002

Chung, K. Y., Lee, S. J., Chung, S. M., Lee, M. Y., Bae, O. N., and Chung, J. H. (2005). Generation of free radical by interaction of iron with thiols in human plasma and its possible significance. Thromb. Res. 116, 157-164. doi: 10.1016/j. thromres.2004.11.021

Connor, J. R., Patton, S. M., Oexle, K., and Allen, R. P. (2017). Iron and restless legs syndrome: treatment, genetics and pathophysiology. Sleep Med. 31, 61-70. doi: 10.1016/j.sleep.2016.07.028

D’Almeida, V., Hipolide, D. C., Azzalis, L. A., Lobo, L. L., Junqueira, V. B., and Tufik, S. (1997). Absence of oxidative stress following paradoxical sleep deprivation in rats. Neurosci. Lett. 235, 25-28. doi: 10.1016/s03043940(97)00706-4

Das, G., Gopalakrishnan, A., Faisal, M., and Mallick, B. N. (2008). Stimulatory role of calcium in rapid eye movement sleep deprivation-induced noradrenalinemediated increase in Na-K-ATPase activity in rat brain. Neuroscience 155, 76-89. doi: 10.1016/j.neuroscience.2008.04.069

\section{AUTHOR CONTRIBUTIONS}

BM conceived the problem and arranged funds for the study. AS, GD and MK carried out the experiments and analyzed the data. All authors contributed to preparing the manuscript, read and agreed with its content.

\section{FUNDING}

AS, GD and MK received fellowships from CSIR and UGC for pursuing their Ph.D. This research was funded by part grants to BM from Indian funding agencies i.e., Indian Council of Medical Research; Department of Biotechnology (DBT), Ministry of Science and Technology; JC Bose Fellowship; University Grants Commission and Institutional umbrella support under DBTBUILDER; Department of Science and Technology (DST), Ministry of Science and Technology (DST-PURSE), -FIST; UGCUPE, -Resource Network and -SAP-DRSI.

Das, G., and Mallick, B. N. (2008). Noradrenaline acting on $\alpha 1$-adrenoceptor mediates REM sleep deprivation-induced increased membrane potential in rat brain synaptosomes. Neurochem. Int. 52, 734-740. doi: 10.1016/j.neuint.2007. 09.002

Demaurex, N., and Scorrano, L. (2009). Reactive oxygen species are NOXious for neurons. Nat. Neurosci. 12, 819-820. doi: 10.1038/nn0709-819

Dinis, T. C., Maderia, V. M., and Almeida, L. M. (1994). Action of phenolic derivatives (acetaminophen, salicylate, and 5-aminosalicylate) as inhibitors of membrane lipid peroxidation and as peroxyl radical scavengers. Arch. Biochem. Biophys. 315, 161-169. doi: 10.1006/abbi.1994.1485

Dröge, W., and Schipper, H. M. (2007). Oxidative stress and aberrant signaling in aging and cognitive decline. Aging Cell 6, 361-370. doi: 10.1111/j.1474-9726. 2007.00294.x

Dugan, L. L., Sensi, S. L., Canzoniero, L. M., Handran, S. D., Rothman, S. M., Lin, T. S., et al. (1995). Mitochondrial production of reactive oxygen species in cortical neurons following exposure to N-methyl-D-aspartate. J. Neurosci. 15, 6377-6388. doi: 10.1523/JNEUROSCI.15-10-06377.1995

Friedman, J. (2011). "Why is the nevous system vulnerable to oxidative stress?," in Oxidative Stress and Free Radical Damage in Neurology, eds N. Gadoth and H. H. Gobel (New York, NY: Humana Press), 19-27.

Galli, F., Piroddi, M., Annetti, C., Aisa, C., Floridi, E., and Floridi, A. (2005) Oxidative stress and reactive oxygen species. Contrib. Nephrol. 149, 240-260. doi: $10.1159 / 000085686$

García, C. R., Angelé-Martinez, C., Wilkes, J. A., Wang, H. C., Battin, E. E., and Brumaghim, J. L. (2012). Prevention of iron- and copper-mediated DNA damage by catecholamine and amino acid neurotransmitters, L-DOPA, and curcumin: metal binding as a general antioxidant mechanism. Dalton Trans. 41, 6458-6467. doi: 10.1039/c2dt30060e

Greengrass, P., and Bremner, R. (1979). Binding characteristics of 3H-prazosin to rat brain $\alpha$-adrenergic receptors. Eur. J. Pharmacol. 55, 323-326. doi: 10.1016/0014-2999(79)90202-4

Gulçin, I. (2008). Measurement of antioxidant ability of melatonin and serotonin by the DMPD and CUPRAC methods as trolox equivalent. J. Enzyme Inhib. Med. Chem. 23, 871-876. doi: 10.1080/14756360701626223

Gulyani, S., and Mallick, B. N. (1993). Effect of rapid eye movement sleep deprivation on rat brain $\mathrm{Na}-\mathrm{K}$ ATPase activity. J. Sleep Res. 2, 45-50. doi: 10.1111/j.1365-2869.1993.tb00060.x

Gulyani, S., and Mallick, B. N. (1995). Possible mechanism of rapid eye movement sleep deprivation induced increase in Na-K ATPase activity. Neuroscience 64, 255-260. doi: 10.1016/0306-4522(94)00333-Z

Gulyani, S., Majumdar, S., and Mallick, B. N. (2000). Rapid eye movement sleep and significance of its deprivation studies'a review. Sleep Hypn. 2, 49-68.

Haber, F., and Weiss, J. (1932). Uber die katalyse des hydroperoxydes. Naturwissenschaften 20, 948-950. doi: 10.1007/bf01504715 
Halliwell, B. (1996). Vitamin C: antioxidant or pro-oxidant in vivo? Nanomedicine $25,439-454$.

Jaiswal, M. K., and Mallick, B. N. (2009). Prazosin modulates rapid eye movement sleep deprivation-induced changes in body temperature in rats. J. Sleep Res. 18, 349-356. doi: 10.1111/j.1365-2869.2008.00731.x

Keen, C. L., Reinstein, N. H., Goudey-Lefevre, J., Lefevre, M., Lönnerdal, B., Schneeman, B. O., et al. (1985). Effect of dietary copper and zinc levels on tissue copper, zinc, and iron in male rats. Biol. Trace Elem. Res. 8, 123-136. doi: $10.1007 / \mathrm{bf} 02917466$

Khadrawy, Y. A., Nour, N. A., and Aboul Ezz, H. S. (2011). Effect of oxidative stress induced by paradoxical sleep deprivation on the activities of $\mathrm{Na}^{+}, \mathrm{K}^{+}$-ATPase and acetylcholinesterase in the cortex and hippocampus of rat. Transl. Res. 157, 100-107. doi: 10.1016/j.trsl.2010.11.005

Kitka, T., Katai, Z., Pap, D., Molnar, E., Adori, C., and Bagdy, G. (2009). Small platform sleep deprivation selectively increases the average duration of rapid eye movement sleep episodes during sleep rebound. Behav. Brain Res. 205, 482-487. doi: 10.1016/j.bbr.2009.08.004

Koul, A., Singh, M., and Gangar, S. C. (2005). Modulatory effects of different doses of $\alpha$-tocopherol on benzo(a)pyrene-DNA adduct formation in the pulmonary tissue of cigarette smoke inhaling mice. Indian J. Exp. Biol. 43, 1139-1143.

Lalkovicova, M., and Danielisova, V. (2016). Neuroprotection and antioxidants. Neural Regen. Res. 11, 865-874. doi: 10.4103/1673-5374.184447

Lebel, C. P., and Bondy, S. C. (1990). Sensitive and rapid quantitation of oxygen reactive species formation in rat synaptosomes. Neurochem. Int. 17, 435-440. doi: 10.1016/0197-0186(90)90025-o

Lee, K. A., Zaffke, M. E., and Baratte-Beebe, K. (2001). Restless legs syndrome and sleep disturbance during pregnancy: the role of folate and iron. J. Womens. Health Gend. Based Med. 10, 335-341. doi: 10.1089/152460901750269652

Leutner, S., Eckert, A., and Muller, W. E. (2001). ROS generation, lipid peroxidation and antioxidant enzyme activities in the aging brain. J. Neural Transm. 108, 955-967. doi: 10.1007/s007020170015

Lowry, O. H., Rosebrough, N. J., Farr, A. L., and Randall, R. J. (1951). Protein measurement with the Folin phenol reagent. J. Biol. Chem. 193, 265-275.

Majumdar, S., and Mallick, B. N. (2005). Cytomorphometric changes in rat brain neurons after rapid eye movement sleep deprivation. Neuroscience 135, 679-690. doi: 10.1016/j.neuroscience.2005.06.085

Mallick, B. N., and Adya, H. V. (1999). Norepinephrine induced $\alpha$-adrenoceptor mediated increase in rat brain Na-K ATPase activity is dependent on calcium ion. Neurochem. Int. 34, 499-507. doi: 10.1016/s0197-0186(99)00025-x

Mallick, B. N., Majumdar, S., Faisal, M., Yadav, V., Madan, V., and Pal, D. (2002). Role of norepinephrine in the regulation of rapid eye movement sleep. J. Biosci. 27, 539-551. doi: 10.1007/bf02705052

Mallick, B. N., and Singh, A. (2011). REM sleep loss increases brain excitability: role of noradrenaline and its mechanism of action. Sleep Med. Rev. 15, 165-178. doi: 10.1016/j.smrv.2010.11.001

Mallick, B. N., Singh, A., and Khanday, M. A. (2012). Activation of inactivation process initiates rapid eye movement sleep. Prog. Neurobiol. 97, 259-276. doi: 10.1016/j.pneurobio.2012.04.001

Mathangi, D. C., Shyamala, R., and Subhashini, A. S. (2012). Effect of REM sleep deprivation on the antioxidant status in the brain of Wistar rats. Ann. Neurosci. 19, 161-164. doi: 10.5214/ans.0972.7531.190405

McDermott, C. M., LaHoste, G. J., Chen, C., Musto, A., Bazan, N. G., and Magee, J. C. (2003). Sleep deprivation causes behavioral, synaptic, and membrane excitability alterations in hippocampal neurons. J. Neurosci. 23, 9687-9695. doi: 10.1523/JNEUROSCI.23-29-09687.2003

Mehta, R., Khan, S., and Mallick, B. N. (2018). Relevance of deprivation studies in understanding rapid eye movement sleep. Nat. Sci. Sleep 10, 143-158. doi: $10.2147 /$ nss.s140621

Mehta, R., Singh, S., Khanday, M. A., and Mallick, B. N. (2017). Reciprocal changes in noradrenaline and GABA levels in discrete brain regions upon rapid eye movement sleep deprivation in rats. Neurochem. Int. 108, 190-198. doi: 10.1016/j.neuint.2017.03.016

Mendelson, W. B., Guthrie, R. D., Frederick, G., and Wyatt, R. J. (1974). The flower pot technique of rapid eye movement (REM) sleep deprivation. Pharmacol. Biochem. Behav. 2, 553-556. doi: 10.1016/0091-3057(74)90018-5

Mosmann, T. (1983). Rapid colorimetric assay for cellular growth and survival: application to proliferation and cytotoxicity assays. J. Immunol. Methods 65, 55-63. doi: 10.1016/0022-1759(83)90303-4
National Research Council Guidelines. (2011). Guide for the Care and Use of Laboratory Animals. 8th Edn. Washington, DC: National Academic Press.

Patri, M., Singh, A., and Mallick, B. N. (2013). Protective role of noradrenaline in benzo[a]pyrene-induced learning impairment in developing rat. J. Neurosci. Res. 91, 1450-1462. doi: 10.1002/jnr.23265

Patrick, L. R. (2007). Restless legs syndrome: pathophysiology and the role of iron and folate. Altern. Med. Rev. 12, 101-112.

Pillai, J. A., and Leverenz, J. B. (2017). Sleep and neurodegeneration: a critical appraisal. Chest 151, 1375-1386. doi: 10.1016/j.chest.2017.01.002

Porkka-Heiskanen, T., Smith, S. E., Taira, T., Urban, J. H., Levine, J. E., Turek, F. W., et al. (1995). Noradrenergic activity in rat brain during rapid eye movement sleep deprivation and rebound sleep. Am. J. Physiol. 268, R1456-R1463. doi: 10.1152/ajpregu.1995.268.6.r1456

Postuma, R. B., Gagnon, J. F., and Montplaisir, J. (2013). Rapid eye movement sleep behavior disorder as a biomarker for neurodegeneration: the past 10 years. Sleep Med. 14, 763-767. doi: 10.1016/j.sleep.2012.09.001

Ranjan, A., Biswas, S., and Mallick, B. N. (2010). Cytomorphometric changes in the dorsal raphe neurons after rapid eye movement sleep deprivation are mediated by noradrenalin in rats. Behav. Brain Funct. 6:62. doi: 10.1186/1744-908 $1-6-62$

Rehncrona, S., Smith, D. S., Akesson, B., Westerberg, E., and Siesjö, B. K. (1980). Peroxidative changes in brain cortical fatty acids and phospholipids, as characterized during $\mathrm{Fe}^{2+}$ - and ascorbic acid-stimulated lipid peroxidation in vitro. J. Neurochem. 34, 1630-1638. doi: 10.1111/j.1471-4159.1980.tb11254.x

Seaver, L. C., and Imlay, J. A. (2004). Are respiratory enzymes the primary sources of intracellular hydrogen peroxide? J. Biol. Chem. 279, 48742-48750. doi: $10.1074 /$ jbc.m 408754200

Singh, U., Devaraj, S., and Jialal, I. (2005). Vitamin E, oxidative stress, and inflammation. Annu. Rev. Nutr. 25, 151-174. doi: 10.1146/annurev.nutr.24. 012003.132446

Singh, R., Kiloung, J., Singh, S., and Sharma, D. (2008). Effect of paradoxical sleep deprivation on oxidative stress parameters in brain regions of adult and old rats. Biogerontology 9, 153-162. doi: 10.1007/s10522-008-9124-z

Somarajan, B. I., Khanday, M. A., and Mallick, B. N. (2016). Rapid eye movement sleep deprivation induces neuronal apoptosis by noradrenaline acting on $\alpha 1$ adrenoceptor and by triggering mitochondrial intrinsic pathway. Front. Neurol. 7:25. doi: 10.3389/fneur.2016.00025

Stookey, L. L. (1970). Ferrozine-a new spectrophotometric reagent for iron. Anal. Chem. 42, 779-781. doi: 10.1021/ac60289a016

Suer, C., Dolu, N., Artis, A. S., Sahin, L., Yilmaz, A., and Cetin, A. (2011). The effects of long-term sleep deprivation on the long-term potentiation in the dentate gyrus and brain oxidation status in rats. Neurosci. Res. 70, 71-77. doi: 10.1016/j.neures.2011.01.008

Tomasini, C., Guidorzi, R., Bianchi, C., and Beani, L. (1992). Clonidine inhibition of norepinephrine release from normal and morphine-tolerant guinea pig cortical slices. J. Neurochem. 58, 1440-1446. doi: 10.1111/j.1471-4159.1992. tb11361.x

Traver, S., Salthun-Lassalle, B., Marien, M., Hirsch, E. C., Colpaert, F., and Michel, P. P. (2005). The neurotransmitter noradrenaline rescues septal cholinergic neurons in culture from degeneration caused by low-level oxidative stress. Mol. Pharmacol. 67, 1882-1891. doi: 10.1124/mol.104.007864

Troadec, J. D., Marien, M., Darios, F., Hartmann, A., Ruberg, M., Colpaert, F., et al. (2001). Noradrenaline provides long-term protection to dopaminergic neurons by reducing oxidative stress. J. Neurochem. 79, 200-210. doi: 10.1046/j.14714159.2001.00556.x

Ullrich, V., and Kissner, R. (2006). Redox signaling: bioinorganic chemistry at its best. J. Inorg. Biochem. 100, 2079-2086. doi: 10.1016/j.jinorgbio.2006.09.019

Valko, M., Izakovic, M., Mazur, M., Rhodes, C. J., and Telser, J. (2004). Role of oxygen radicals in DNA damage and cancer incidence. Mol. Cell. Biochem. 266, 37-56. doi: 10.1023/b:mcbi.0000049134.69131.89

Vallyathan, V., and Shi, X. (1997). The role of oxygen free radicals in occupational and environmental lung diseases. Environ. Health Perspect. 105, 165-177. doi: $10.2307 / 3433405$

Vogel, G. W. (1975). A review of REM sleep deprivation. Arch. Gen. Psychiatry 32, 749-761. doi: 10.1001/archpsyc. 1975.01760240077006

Wang, G., Hu, W., Tang, Q., Wang, L., Sun, X. G., Chen, Y., et al. (2016a). Effect comparison of both iron chelators on outcomes, iron deposit, and 
iron transporters after intracerebral hemorrhage in rats. Mol. Neurobiol. 53, 3576-3585. doi: 10.1007/s12035-015-9302-3

Wang, B., Wang, Y., Wu, Q., Huang, H. P., and Li, S. (2017). Effects of $\alpha 2 \mathrm{~A}$ adrenoceptors on norepinephrine secretion from the locus coeruleus during chronic stress-induced depression. Front. Neurosci. 11:243. doi: 10.3389/fnins. 2017.00243

Wang, J. Y., Zhuang, Q. Q., Zhu, L. B., Zhu, H., Li, T., Li, R., et al. (2016b). Meta-analysis of brain iron levels of Parkinson's disease patients determined by postmortem and MRI measurements. Sci. Rep. 6:36669. doi: 10.1038/srep36669

Washburn, M., and Moises, H. C. (1989). Electrophysiological correlates of presynaptic $\alpha$ 2-receptor-mediated inhibition of norepinephrine release at locus coeruleus synapses in dentate gyrus. J. Neurosci. 9, 2131-2140. doi: 10.1523/JNEUROSCI.09-06-02131.1989

Yanik, G., and Radulovacki, M. (1987). REM sleep deprivation up-regulates adenosine A1 receptors. Brain Res. 402, 362-364. doi: 10.1016/00068993(87)90046-1

Yen, G. C., and Hsieh, C. L. (1997). Antioxidant effects of dopamine and related compounds. Biosci. Biotechnol. Biochem. 61, 1646-1649. doi: 10.1271/bbb. 61.1646
Zecca, L., Youdim, M. B., Riederer, P., Connor, J. R., and Crichton, R. R. (2004). Iron, brain ageing and neurodegenerative disorders. Nat. Rev. Neurosci. 5, 863-873. doi: 10.1038/nrn1537

Zhang, L., Zhang, H. Q., Liang, X. Y., Zhang, H. F., Zhang, T., and Liu, F. E. (2013). Melatonin ameliorates cognitive impairment induced by sleep deprivation in rats: role of oxidative stress, BDNF and CaMKII. Behav. Brain Res. 256, 72-81. doi: 10.1016/j.bbr.2013.07.051

Conflict of Interest Statement: The authors declare that the research was conducted in the absence of any commercial or financial relationships that could be construed as a potential conflict of interest.

Copyright (C) 2019 Singh, Das, Kaur and Mallick. This is an open-access article distributed under the terms of the Creative Commons Attribution License (CC BY). The use, distribution or reproduction in other forums is permitted, provided the original author(s) and the copyright owner(s) are credited and that the original publication in this journal is cited, in accordance with accepted academic practice. No use, distribution or reproduction is permitted which does not comply with these terms. 